\title{
CUENTAS Y COLGANTES CAMPANIFORMES Y EPICAMPANIFORMES DE CERDEÑA
}

\author{
SARDINIAN BEADS AND BELL BEAKER AND EPI BELL BEAKER PENDANTS
}

\author{
CLAUDIA PAU \\ Universidad de Granada
}

\section{INTRODUCCIÓN}

\subsection{CERDEÑA EN EPOCA CAMPANIFORME}

En la isla de Cerdeña, en el centro del Mediterráneo, han aparecido abundantes restos campaniformes. Teniendo en cuenta las últimas actualizaciones publicadas por M. G. Melis, en 2010 (Melis, 2010, 292 y 295) calculamos que hay más de 70 yacimientos, calcolíticos, con testimonios campaniformes, ubicados principalmente en el área occidental de la isla, aunque también son abundantes los restos documentados en las áreas central y la meridional. A estos yacimientos se deben añadir también los pertenecientes al Bronce Antiguo, donde continúan las manifestaciones campaniformes, como Cuccuru Nuraxi, Settimo San Pietro e Is Calitas, Soleminis, que algunos autores colocan en una fase final del campaniforme (epicampaniforme) mientras que otros, sitúan ya en la Cultura de Bonnanaro.

Testimonios campaniformes se han hallado, en los poblados de Monte Ossoni de Castelsardo, Monte Olladiri de Monastir, y Palazzu de Samassi y en las cabañas de Monte d'Accoddi, Sassari. Se han localizado también fragmentos campaniformes en la gruta de Filiestru, Mara, en el abrigo de Frattale, Oliena y en la Gruta de Sa Ucca de Su Tintirriolu de Mara, usadas como lugares de habitación o santuarios (Contu, 2006, 358-359; Ferrarese Ceruti, 1974, 179-180; 1981, LVI; 1988, 456; 1997, 326 у 477).

La consistente documentación campaniforme en Cerdeña procede casi exclusivamente de los yacimientos funerarios. Se trata fundamentalmente de reutilizaciones, o evidencias de uso continuado, de estructuras construidas en épocas más antiguas. La mayoría de ellas se consideran realizadas en la Cultura de Ozieri, Neolítico Reciente o Final (a partir del 3800/3500 cal A.C.), en otras el registro arqueológico encontrado, comienza con hallazgos Calcolíticos (desde principio del III milenio cal A.C.), y tenemos un único caso de sepultura que se pueda considerar construida en época campaniforme (a partir de mediados del III milenio cal A.C.), la tumba en cista lítica de Santa Vittoria de Nuraxinieddu. Muchas tumbas fueron reutilizadas, además, en la Cultura de Bonnanaro (desde fines del III milenio cal A.C.) mientras que otras sepulturas se usaron hasta la época Nurágica (II milenio cal A.C.) e incluso en el periodo romano o medieval. La tipología tumbal es muy variada: cuatro grutas naturales, dos tumbas en cista lítica (Santa Vittoria en Nuraxinieddu, S'Arrieddu en Cabras), un dolmen (Motorra en Dorgali), dos tumbas hipogeico-megalíticas (la tumba A de Pranu Mutteddu en Goni y Bingia 'e Monti en Gonnostramatza), y sobre todo tumbas hipogeicas, las $d o-$ mus de janas (que significa «las casas de las hadas»), cuevas artificiales, sepulcros excavados en la roca (Pau, 2010, 121-132).

\section{2. LOS ESTUDIOS CRONOLOGICOS}

En Cerdeña desde el Neolítico hasta el Bronce Antiguo se sucedieron numerosas facies arqueológicas (Fig. 1). Según los estudios más actuales las fases culturales que se han definido para el Neolítico sardo (aproximadamente entre el 6000 y el 3200 cal A.C.) son, en orden cronológico, las culturas de Su Carropu, de Grotta Verde, de Filiestru B (Neolítico Antiguo), la cultura de Bonu Ighinu (Neolítico Medio), la cultura de San Ciriaco (Neolítico Reciente) y la cultura de San Michele de Ozieri (Neolítico Final). El Calcolítico (entre el 3200 y el 2200 cal A.C.), se suele subdividir en 6 fases culturales, culturas de Sub Ozieri y de Filigosa (Calcolítico Antiguo), cultura de Albealzu (Calcolítico Medio), cultura de Monte Claro (Calcolítico Reciente) y Campaniforme A (Calcolítico Final cuyo desarrollo en parte puede ser coetáneo al de la cultura de Monte Claro). El Campaniforme continuaría en una última fase, Campaniforme B, en el Bronce Antiguo I (Ugas, 2005, 11-18).

En realidad, el estudio del desarrollo del Campaniforme en la isla ha sido muy complicado y ya desde el 


\begin{tabular}{|c|c|c|c|c|}
\hline PERIODO & FASE & CULTURA & CRONOLOGÍAA. C. & $\begin{array}{r}\text { CRONOLOGÍA } \\
\text { CALIBRADA a.C }\end{array}$ \\
\hline \multirow{6}{*}{ Neolítico } & Antiguo I & Su Carropu & $6000-4700$ & \multirow{3}{*}{$6000-4700$} \\
\hline & Antiguo II & Grotta verde & $4700-4300$ & \\
\hline & Antiguo III & Filiestru B & $4300-4000$ & \\
\hline & Medio & Bonu Ighinu & $4000-3400$ & $4700-4000$ \\
\hline & Reciente & San Ciriaco & $3400-3200$ & \multirow{3}{*}{$4000-3200$} \\
\hline & Final & S. Michele-Ozieri & $3200-2850$ & \\
\hline \multirow{7}{*}{ Calcolítico } & Inicial & & & \\
\hline & Antiguo I & Sub Ozieri & $2850-2700$ & \multirow{3}{*}{$3200-2700$} \\
\hline & Antiguo II & Filigosa & $2700-2600$ & \\
\hline & Medio & Albealzu & $2600-2400$ & \\
\hline & Reciente & Monte Claro & $2400-2100$ & \multirow{3}{*}{$2700-2200$} \\
\hline & Final I & Campaniforme A1 & $2100-2000$ & \\
\hline & Final II & Campaniforme A2 & $2000-1900$ & \\
\hline \multirow{3}{*}{ Bronce } & Antiguo I & $\begin{array}{l}\text { Campaniforme B } \\
\text { (Epicampaniforme) }\end{array}$ & $1900-1800$ & \multirow{3}{*}{$2200-1900$} \\
\hline & Antiguo II & Bonnanaro A1 & $1800-1650$ & \\
\hline & Antiguo III & Bonnanaro A2 & $1650-1600$ & \\
\hline
\end{tabular}

Figura 1: Cronología y facies culturales de Cerdeña desde el Neolítico hasta el Bronce Antiguo, según G. Ugas (2005).

descubrimiento de los primeros testimonios se discutió sobre sus aspectos cronológicos y culturales, siendo los cuadros cronológicos más seguidos los desarrollados por M. L. Ferrarese Ceruti, E. Contu, E. Atzeni y G. Ugas.

M. L. Ferrarese Ceruti habló de un momento más antiguo donde el Campaniforme se superpone, aunque parcialmente, a la Cultura Calcolítica de Monte Claro, en que se percibirían influjos occidentales (Península Ibérica, Francia meridional). Este momento quedaría atestiguado en los yacimientos de Monte Ossoni de Castelsardo (Sassari), Monte Olladiri de Monastìr y Palazzu de Samassi (Cagliari), donde se han hallado elementos campaniformes en asociación con elementos de Cultura Monte Claro, mientras que serían prueba de la mayor antigüedad de los restos Monte Claro, las superposiciones estratigráficas en Padru Jossu en Sanluri, Pani-Lòriga en Santadi, y la tumba VII de Serra Is Araus en San Vero Milis. La autora habla también de un momento más reciente (inicio del Bronce Antiguo), caracterizado por fuertes influjos centroeuropeos. Además M. L. Ferrarese Ceruti, situó los ajuares de los niveles superiores de las sepulturas de Padru Jossu, Sanluri, y de Marinaru, Porto Torres entre el final del Eneolítico y el Bronce Antiguo. Por lo tanto, para esta investigadora los inicios del Campaniforme en Cerdeña se colocarían en el último cuarto del tercer milenio a. C. en fechas no calibradas (Ferrarese Ceruti, 1981, LV; 1988, 456; 1989, 60-61; 1997, 325 y 477-478).

E. Contu, encuadra el desarrollo del campaniforme entre los últimos siglos del III y los primeros del II milenio a.C.(también en fechas no calibradas). Para este autor las primeras manifestaciones aparecerían antes del final de Filigosa, para después perdurar, junto con manifestaciones Monte Claro, también después de Albeazu, hibridándose con sucesivos elementos de la Cultura Bonnanaro. E. Contu, puntualiza que hay claros indicios estratigráficos de un periodo únicamente con campaniforme en Cerdeña, identificable en algunos yacimientos como Padru Jossu y Santu Pedru, aunque, en nuestra opinión sea una imagen resultado del carácter de estos contextos. Este investigador, indica una evolución del campaniforme en fases y basándose en las dataciones de carbono 14 del Eneolítico sardo de la Gruta de Filiestru, Mara (Sassari) propone para el inicio del campaniforme sardo decorado, la fecha no calibrada de 2300-2000 a. C. aproximadamente (2860-2350 cal A.C.) y además coloca la última fase (cerámicas con perfiles rígidos y redondeados y con asas a codo, vasos trípodes y ausencia de decoraciones) en el Bronce Antiguo, en la primera fase de la facies de Bonnanaro (Bonnanaro I) (2000-1600 a.C.; 2350-1800 cal A. C.) (Contu, 1988, 442; 1996, 385396; 2006, 388-389 y417).

Para E. Atzeni, el campaniforme se manifiesta en Cerdeña desde el Eneolítico a la primera edad del Bronce (últimos siglos del III milenio y los primeros del II milenio a. C.), superponiéndose a la cultura de Monte Claro, sin excluir posibles contactos con la Cultura de Albeazu-Filigosa y declinando en las facies del Bronzo Antiguo. El autor propuso una secuencia en 4 fases del campaniforme sardo. Una fase antigua, atestiguada por escasos hallazgos de tipología arcaica, como un fragmento cerámico de pasta fina y superficies bruñidas con decoración cordada (gruta de Corongiu Acca I, Villamassargia), y vasos en forma de campana en estilo marítimo. La siguiente fase media constituiría, para él, el momento más típico, caracterizado por la convergencia de influjos de las provincias campaniformes europeas. La fase reciente, que, para él, se puede sincronizar con aspectos extra insulares de transición al primer bronce, mostraría una fuerte 
continuidad con la anterior, aunque presentando nuevas tipologías vasculares y nuevos estilos decorativos, tal vez con connotaciones regionales como muestran los vasos de la zona del Sulcis Iglesiente. En una fase final, las últimas manifestaciones campaniformes se atestiguarían en pleno Bronce Antiguo, en un nuevo ámbito cultural correspondiente a las facies de Bonnanaro A, por primera vez documentada en los hipogeos de Corona Montana, Bonnanaro. En esta fase el repertorio cerámico está caracterizado por una disminuación de la decoración y con vasos con asas, trípodes con cuerpo troncocónico o carenados con altos pies subrectangulares, copas de tipo frutero con pie hueco, ollitas y formas carenadas, bicónicas o troncocónicas. Todavía perduran los brazaletes de arquero, los punzones en cobre, algunos ornamentos en hueso y concha y los colmillos de jabalí, y aparece por primera vez el puñalito sin codo con la placa de enmangue redondeada y con los agujeros para los remaches (Atzeni, 1996, 397-408; 1998a, 243-253).

Según el esquema cronológico propuesto por G. Ugas, en Cerdeña los materiales de las facies campaniformes se encuentran claramente superpuestos a los de la Cultura de Monte Claro, como está bien delineado en las secuencias estratigráficas de Padru Jossu en Sanluri, Santu Pedru en Alghero, y Su Crocifissu Mannu en Porto Torres. Para él, esto indicaría la plena autonomía del aspecto sardo del campaniforme internacional con respecto al Monte Claro, mientras que parece posible una parcial contemporaneidad de este último con la fase cordada campaniforme, si bien ello supondría acortar considerablemente el desarrollo de las facies calcolíticas no campaniformes. Para este investigador, el campaniforme, se desarrollaría en dos fases del Eneolítico Final (A1, facies marítima-internacional; A2, facies italiana-sulcitana o de Locci Santus), aproximadamente 2100-1900 a. C. en fechas no calibradas, y de una del Bronce Antiguo Inicial (B, facies del campaniforme «inornato» sin decoración o de Padru Jossu B), aproximadamente1900-1800 a. C., indicadora de los contactos entre Cerdeña y las regiones mediterráneas franco-ibéricas y además con Europa centro-occidental (Ugas, 1998a, 254-255; 2005, 17).

Actualmente, muchos estudiosos, colocan cronológicamente el campaniforme sardo, sobre la base de dos dataciones, entre las obtenidas del estudio del hipogeo de Padru Jossu, Sanluri 2463 y el 2155 cal A.C., (Melis, 2010, 292), lo que además coincide con el desarrollo en áreas vecinas.

Teniendo en cuenta estas interpretaciones, consideramos que los testimonios campaniformes aparecen en el Calcolítico local, durante el desarrollo de la Cultura Monte Claro, a mediados del III Milenio cal A.C., y perdurarían con sus más tardías manifestaciones (lo que denominamos epicampaniforme) en los momentos iniciales de la antigua edad del Bronce, a inicios del II Milenio cal A.C. como atestiguan, por ejemplo los casos de las tumbas de Cuccuru Nuraxi, Settimo San Pietro e Is Calitas, Soleminis. Por lo tanto, también en Cerdeña el Campaniforme pasará desde unas primeras fases con las formas típicas de ámbito europeo, a una fuerte regionalización con diferenciaciones zonales, hasta hibridarse en las facies iniciales del Bronce Antiguo.

\section{3. LA CULTURA MATERIAL}

En Cerdeña encontramos vasijas cerámicas con pasta de buena calidad, las formas más características son los típicos vasos en forma de campana invertida, con perfil redondeado o, sobre todo, carenado y con el fondo plano, los cuencos hemisféricos, a veces con tres o cuatro pies en la mayoría de los casos cilíndricos, tazas troncocónicas con una sola asa y jarras. En la isla se atestigua un único vaso con decoración cordada, el ejemplar de la Gruta de Coròngiu Acca I, Villamassargia (Atzeni, 1996, 397), mientras que hay una gran difusión de elementos con decoración en peine o con incisión simple. En algunos casos las dos técnicas están presentes en un único vaso. Las decoraciones se realizan en bandas horizontales en intervalo con zonas lisas lo que es característico de todos los vasos del estilo denominado «marítimo» o internacional. A veces la decoración campaniforme internacional, con bandas rellenada de tratos oblicuos, se enriquece de triángulos con puntillado horizontal; mientras que en los vasos polípodos se utilizan las técnicas del campaniforme mediterráneo con las típicas bandas lisas en zig-zag obtenidas por la oposición alterna de los vértices de los triángulos adornados con trazos. Frecuentes son también los motivos en reticulado, mientras son raros los motivos en ajedrez y los metopados (Ferrarese Ceruti, 1981, LVIX; 1997, 329).

En Cerdeña encontramos las armas típicas del campaniforme europeo, puntas de flecha, puñales triangulares, y brazaletes de arquero, aunque no hayan aparecido puntas de tipo Palmela. Se puede suponer que algunas hachas pulidas y cuchillos de sílex u obsidiana pertenezcan al campaniforme isleño, aunque es difícil su identificación no teniendo caracteres distintivos (Contu, 2006, 369). Pueden también pertenecer a la misma época, los punzones en cobre, puntiagudos en las dos extremidades, con sección cuadrada o circular, con uso continuado también en el Bronce Antiguo (Contu, 2006, 369; Ferrarese Ceruti, 1997, 333).

El campaniformes de Cerdeña presenta, un gran repertorio de elementos de ornamento, collares, cuentas, colgantes, botones, brazaletes (pulseras o tobilleras) y alfileres, además, de un disco en lámina de plata, con agujeros, interpretado como un espejo (Pau, 2008)

\section{3. LOS OBJETOS DE ADORNOS: CUENTAS Y COLGATES}

Teniendo en cuenta las aportaciones de los estudios sobre adornos en la investigación arqueológica (Barciela González, 2008; Barge, 1982; Pérez Arrondo y 


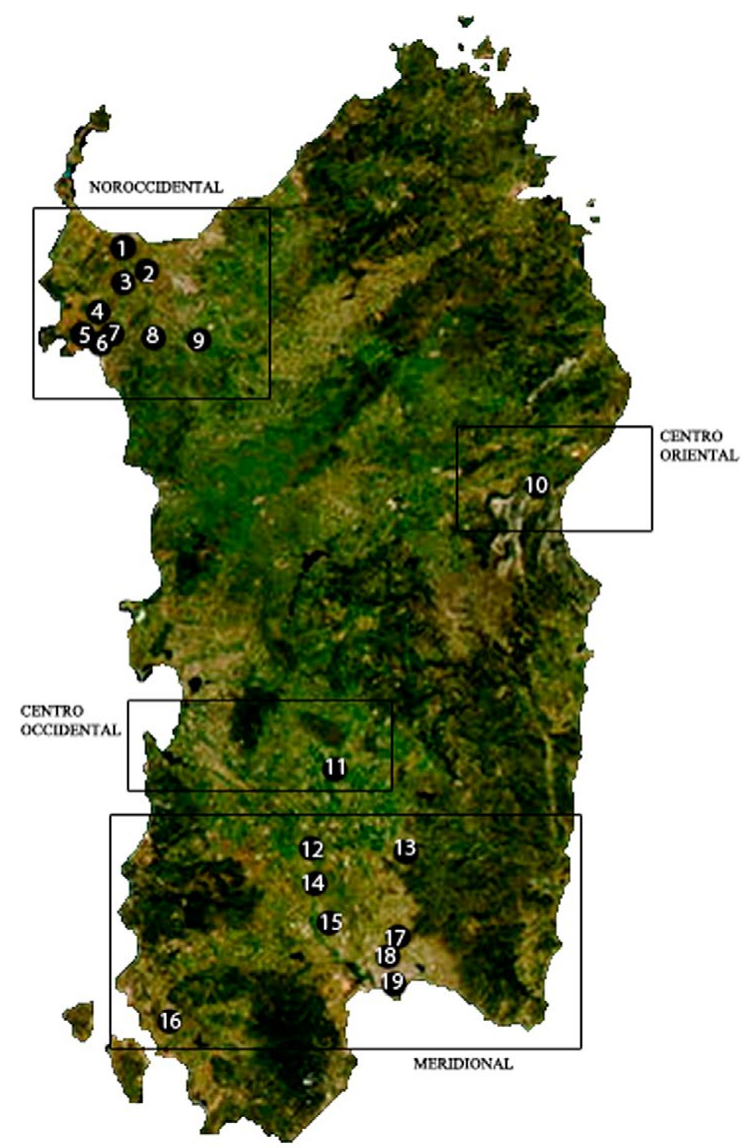

1. Su Crocifissu Mannu. Porto Torres

2. Marinaru. Porto Torres

3. Ponte Secco. Porto Torres

4. Anghelu Ruyu. Alghero

5. Cuguttu. Alghero

6. Taulera. Alghero

7. Santu Pedru. Alghero

8. S'Elighe Entosu. Usini

9. S' Adde'e Asile. Ossi

10. Motorra. Dorgali

11. Bingia 'e Monti. Gonnostramatza

12. Padru Jossu. Sanluri

13. Monte Luna. Senorbí

14. Palazzu. Samassi

15. Sant'Iroxi. Decimoputzu

16. Locci Santus. San Giovanni Suergiu

17. Is Calitas. Soleminis

18. Cuccuru Nuraxi. Settimo San Pietro

19. Capo S. Elia. Cagliari

Figura 2: Yacimientos con cuentas y colgantes campaniformes y epicampaniformes de Cerdeña.

López de la Calle Cámara, 1985; Taborin, 2004), y además considerando las escasas investigaciones realizadas en este sector tan importante en relación a la época campaniforme y epicampaniforme de Cerdeña, con respecto a otros materiales (cerámica, armas, etc.), hemos considerado oportuno focalizar nuestro trabajo en el análisis de dos categorías de adornos, las de las cuentas y las de los colgantes, que se hallaron en los yacimientos campaniformes y epicampaniformes de Cerdeña (Fig. 2).

Estos elementos sueltos (cuentas y colgantes) podrían pertenecer a collares, pero también a brazaletes, tobilleras, pendientes, cinturones o, quizás, podían simplemente haber sido utilizados como elementos decorativos del pelo o de las vestimentas.

La mayoría de estos objetos de adorno presentan una perforación (Fig. 3), que nos indicaría indudablemente su uso, ensartadas en un hilo o unas cuerdas

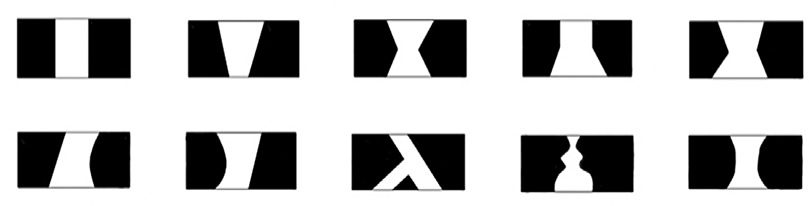

Figura 3: Diferentes tipos de perforaciones de cuentas y colgantes campaniformes y epicampaniformes de Cerdeña. sutiles de fibras vegetales o cuero de animal o cosidos; otros están sin perforación. En este último caso puede tratarse de elementos en fase de elaboración, o podían ser pequeños amuletos protectores depositados en las tumbas, o también se podría pensar que estas gentes prehistóricas utilizaran pegamentos vegetales o animales, con los cuales adherir estos pequeños elementos, cuyas trazas habrían desaparecido con el tiempo.

Se han definido como cuentas los elementos sueltos que presentan una anchura superior o igual a la altura y como colgantes las joyas que penden o cuelgan, porque tienen una altura siempre superior respecto a la anchura.

En el presente trabajo, se han clasificado los elementos más recurrentes en los contextos sardos, y los más característicos. Las categorías de cuentas y colgantes se han ordenado en grupos (Fig. 4) siguiendo criterios morfológicos, poniendo en relación todos los objetos que presentan una forma similar. Cada grupo ha sido, posteriormente dividido en subgrupos teniendo en cuanta el soporte sobre el que han sido manufacturados; además hay subgrupos que han sido articulados en diferentes tipos según aspectos morfológicos (influyendo en algún caso en la funcionalidad del objeto).

En este modo queremos dar un cuadro preciso de las diferentes variedades de cuentas y colgantes, que 

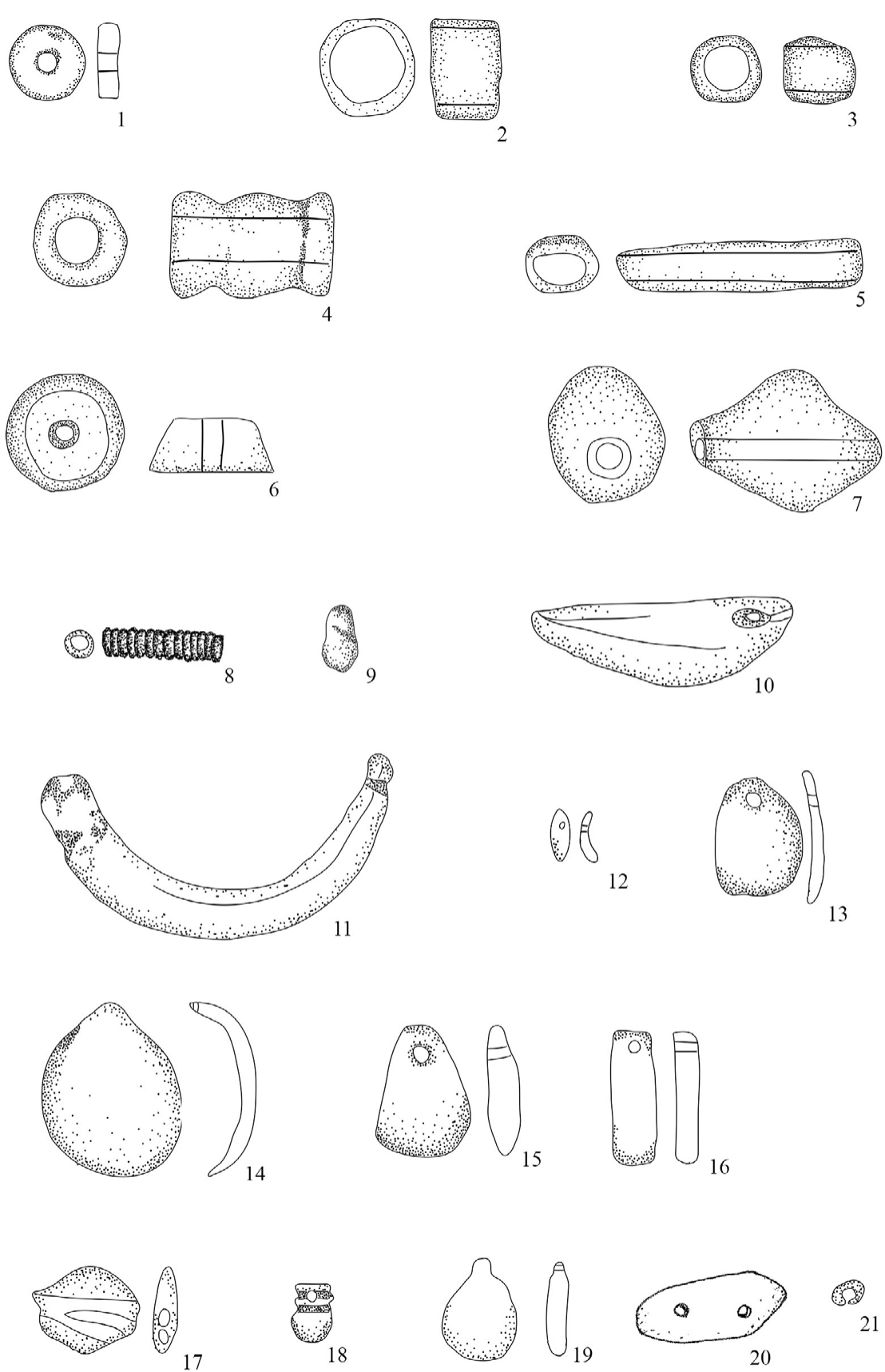

Figura 4: Categoría 1 Cuentas: 1. Grupo I Cuentas discoidales (Monte Luna, Senorbí); 2. Grupo II Cuentas cilíndricas o tubulares (Anghelu, Ruju, Alghero); 3. Grupo III Cuentas en «oliva» (Padru Jossu, Sanluri); 4. Grupo IV Cuentas con apéndices laterales o a glóbulos (Padru Jossu, Sanluri); 5. Grupo V Cuentas de concha entera (Padru Jossu, Sanluri) (Ugas, 1998b, 267, fig. 7 reelaborado); 6. Grupo VI Cuentas troncocónicas (Colección Doneddu, Carbonia); 7. Grupo VII Cuentas bicónicas (Bingia e' Monti, Gonnostramatza); 8. Grupo VIII Cuentas en espiral (Cuguttu, Alghero); 9. Grupo IX Perles à ailettes (cuentas con alitas) (Padru Jossu, Sanluri). Categoría 2 Colgantes: 10. Grupo X Colgantes de diente entero (Padru Jossu, Sanluri); 11. Grupo XI Colgantes en forma de creciente lunar (Padru Jossu, Sanluri); 12. Grupo XII Colgantes ovales (Isa Calitas, Soleminis) (Manunza et alii, 2005, 169 51d); 13 . Grupo XIII Colgantes laminares en concha (Padru Jossu, Sanluri); 14. Grupo XIV Colgantes de concha entera (Ponte Secco, Porto Torres); 15. Grupo XV Colgantes en forma de hacha (Su Crocifissu Mannu, Porto Torres); 16. Grupo XVI Colgantes rectangulares (Colleción Doneddu, Carbonia); 17. Grupo XVII Colgantes romboidales (Padru Jossu, Sanluri); 18. Grupo XVIII Colgantes en forma de corazón (Padru Jossu, Sanluri); 19. Grupo XIX Colgantes globulares o planos con apéndices para la suspensión (Anghelu Ruju, Alghero); 20. Grupo XX Fíbulas-colgantes (Padru Jossu, Sanluri) (Ugas, 1998b, 269, fig.9 reelaborado); 21. Grupo XXI Anillos-colgantes (Cuguttu, Alghero) (Castillo Yurrita, 1928, lám. CXV reelaborado). 
aparecieron en Cerdeña durante el periodo de difusión e hibridación del fenómeno campaniforme, y poder estimar la aparición de nuevas formas, la persistencia de elementos utilizados en anteriores facies culturales, y los cambios en la elección y en el uso de los soportes, además realizando comparaciones con materiales afines de las regiones europeas, será posible medir los posibles contactos y relaciones que, al final del Calcolítico y al inicio del Bronce Antiguo, interesaron a la isla de Cerdeña en el arco Mediterráneo.

\section{LAS CUENTAS}

\subsection{CUenTAS DisCOIDALES}

Se han estudiado las cuentas de forma discoidal (grupo I) (Fig. 5. 36-52), halladas en catorce yacimientos
(Capo Sant' Elia, Padru Jossu, Monte Luna, Cuccuru Nuraxi, Is Calitas, Bingia 'e Monti, Motorra, Anghelu Ruju, Cuguttu, Santu Pedru, Taulera, Ponte Secco, Su Crocifissu Mannu, S'Elighe Entosu) (AA.VV., 1990, 72; Atzeni, 1998a, 252, Fig. 8; 2003, lám. 1; 2007, 5253; Contu, 1955, 27; 1964, 187-188; Ferrarese Ceruti, 1974, 167, Fig. 22; 1997, 193-194 nota 184; Lilliu, 1968, 81; Manca, 2010, 240; Manunza et alii., 2005, 145; Taramelli, 1904, 1909a, 1909b; Ugas, 1998b, 267, Fig. 7).

Se trata de pequeños elementos de morfología discoidal (diámetro mínimo 0,2 cm, máximo 1,9 cm; espesor mínimo $0,1 \mathrm{~cm}$, máximo $0,8 \mathrm{~cm}$ ), con las caras de forma circular y sección plana o ligeramente planocóncava, cóncavo-convexa o plano-convexa, con una perforación central transversal a su eje máximo, de forma circular o ligeramente ovalada y sección cilíndrica y en algunos casos bicónica, troncocónica, o irregular.

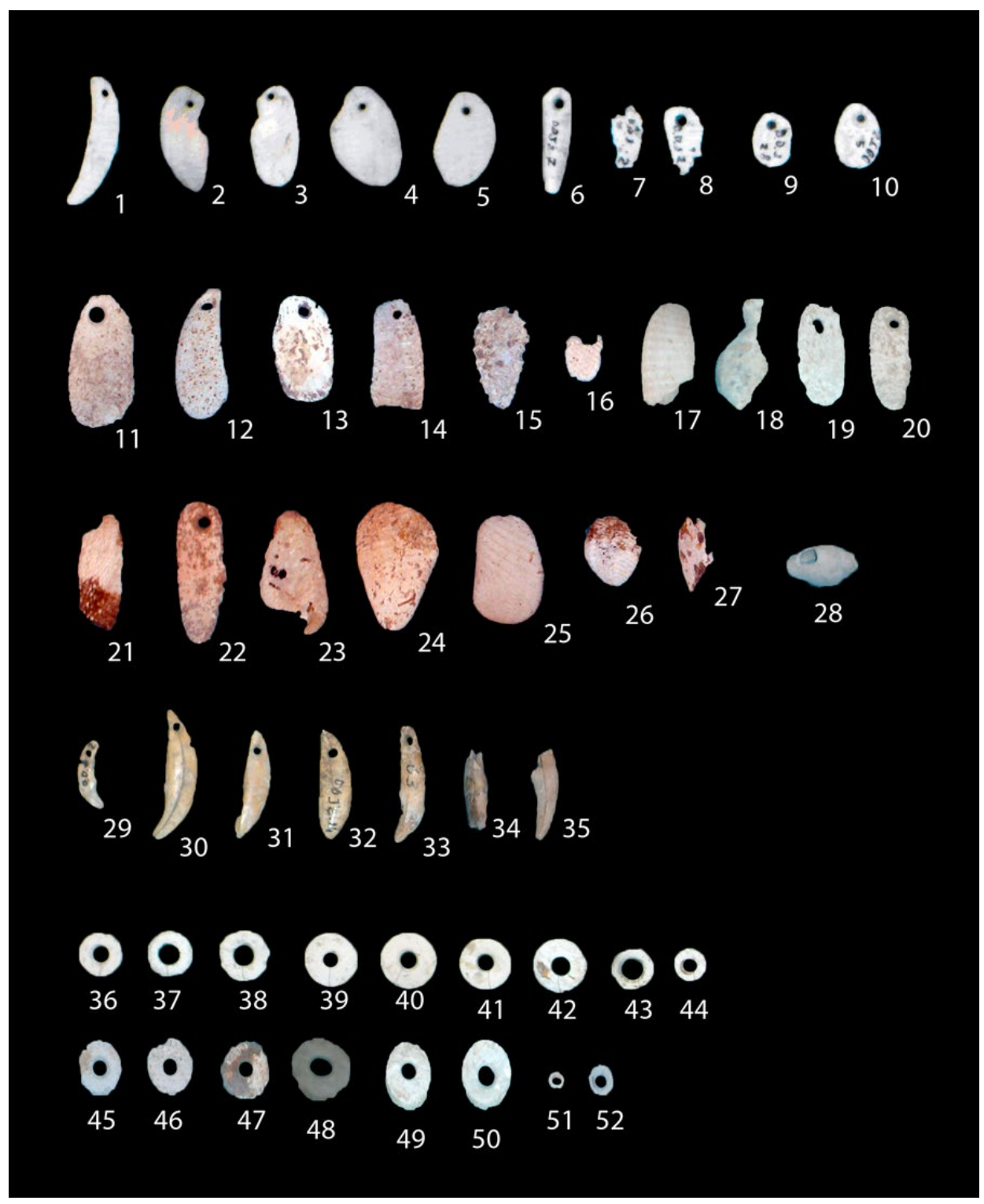

Figura 5: 1-27. Colgante en concha; 28. Colgante en concha entera; 29-35. Colgantes obtenidos de dientes de animales; 36-52. Cuentas discoidales (Monte Luna, Senorbí). 
Estas piezas, aparecen en toda la secuencia del campaniforme sardo desde las fases iniciales hasta las finales en el Bronce antiguo inicial, y están documentadas uniformemente en toda el área estudiada, y en todas las tipologías tumbales.

Hay cuatro subgrupos de cuentas discoidales, el primero (subgrupo I) está constituido por elementos elaborados desde los exoesqueletos de bivalvos (familia Cardiidae. Glycymerididae) o gasterópodos (familia Ranellidae), y se han hallado en doce de los yacimientos estudiados (Capo Sant' Elia, Padru Jossu, Monte Luna, Cuccuru Nuraxi, Is Calitas, Bingia 'e Monti, Anghelu Ruju, Santu Pedru, Taulera, Ponte Secco, Su Crocifissu Mannu, S'Elighe Entosu) (AA. VV., 1990, 72; Atzeni, 1998a, 252, Fig. 8; 2003, lám. 1.2.; 2007, 52-53; Contu, 1955, 27; 1964, 187-188; Ferrarese Ceruti, 1974, 167, Fig. 22; 1997, 193-194 nota 184; Manca, 2010, 240; Manunza et alii, 2005, 145; Taramelli, 1904, 1909a, 1909b; Ugas, 1998b, 267, Fig. 7). Estos ornamentos en concha se conocen en Cerdeña ya desde el Neolítico, y parecen muy apreciados también en periodo campaniforme y epicampaniforme. El segundo subgrupo de cuenta discoidal (subgrupo II), estaba elaborado en roca. Dos elementos en esquisto (roca metamórfica) fueron hallados en la tumba XXX de Anghelu Ruju, Alghero (Taramelli, 1909a, 512), y en la tumba I o «Tomba Bassu» de Ponte Secco, Porto Torres (Contu, 1955, 35). En mineral (subgrupo III), hay un elemento en calcedonia del dolmen de Motorra en Dorgali (Lilliu, 1968, 81) mientras una cuenta de color verde azulado, probablemente talco (esteatita), es uno de los elementos que constituyen, como veremos más adelante, el collar procedente de la tumba XXX de Anghelu Ruju (AA.VV., 1998, 296; Taramelli, 1909a, 504-515). Hay también un tipo de cuenta en hueso de animal (subgrupo IV), con los ejemplares de Cuguttu, Alghero (Taramelli, 1909b, 102), el hallazgo de la «Tomba Bassu»(Contu, 1955, 27), o el ornamento conservado en uno de los collares de Bingia e' Monti, Gonnostramatza (AA.VV., 1998, 305), aunque el último de dimensiones mayores y de morfología más aplanada.

En Cerdeña este grupo de ornamentos, ya conocidos desde el neolítico y utilizados ampliamente sobre todo durante la Cultura de Ozieri, la época campaniforme, y la cultura Bonnanaro (Ferrarese Ceruti, 1974, 166-168), continuará a ser imitado también en épocas sucesivas durante la cultura nurágica en arenisca, esquisto o talco (esteatita) (Fois, 2000, 37). Las cuentas discoidales son conocidas en toda el área europea donde se manifestó el fenómeno campaniforme, en particular debemos citar los centros de producción, de cuentas discoidales en concha, localizados en el Ariège y en el Herault en la Francia Meridional (Ferrarese Ceruti, 1997, 334), y en la Península Italiana, los centros de producción de cuentas y colgantes en talco (esteatita), como el de la Puzzolente, (Livorno) (Sammartino, 1990), y el de la Pianaccia de Suvero, (La Spezia) (Maggi, 1990, Maggi et alii, 1987), donde se han hallado objetos en curso de elaboración y manufacturados, entre los cuales hay numerosos elementos discoidales.

\subsection{Cuentas CILÍNDRICAS O TUBULARES}

Las cuentas cilíndricas o tubulares, que constituyen el grupo II, presentan morfología cilíndrica, y sección circular con una perforación central circular o ligeramente ovalada y sección cilíndrica, o troncocónica en sentido longitudinal a su eje máximo. En este grupo hay cuentas en concha (Ranellidae, Dentaliidae) (subgrupo I), en roca sedimentaria (caliza) (subgrupo II) y en mineral (serpentina) (subgrupo III). Tienen un tamaño entre los 1,4 y $4,3 \mathrm{~cm}$ de longitud, 0,4 y $0,8 \mathrm{~cm}$ de diámetro y 0,85 y $1,4 \mathrm{~cm}$ de ancho.

Hemos estudiado un total de cuarenta y dos cuentas pertenecientes a este grupo morfológico, de las cuales cuarenta fueron halladas en yacimientos de la Cerdeña noroccidental, siempre en contextos funerarios, y además treinta y ocho provenientes de la misma necrópolis, veinte de la tumba I y dieciocho de la tumba XXX de la necrópolis de Anghelu, Ruju, Alghero (Taramelli, 1904, 322; 1909a, 504-515). De la Cerdeña meridional proceden sólo dos piezas, una de Is Calitas, Soleminis, (Manunza et alii, 2005, 175) y otra conservada en uno de los collares del Estrato II de Padru Jossu, Sanluri (AA.VV., 1998, 327).

La concentración de estos ornamentos, conocidos en contextos campaniformes europeos, en sólo cuatro yacimientos de Cerdeña hace difícil realizar deducciones sobre el significado de su distribución, también porque esta circunstancia puede depender de una laguna derivada del estado actual de la investigación, y no a un escaso interés por parte de las gentes campaniformes respecto a este tipo de ornamento, sobre todo teniendo en cuenta que cuentas cilíndricas aparecen en Cerdeña ya en el Neolítico (Contu, 2006, 210), perdurando hasta época Nuragica (Fois, 2000, 46).

Dos elementos (subgrupo I), de la Tumba I o Tomba dei vasi tetrapodi de Santu Pedru, (Contu, 1964, 65 y 187-188) han sido obtenidos trabajando el exoesqueleto de un gasterópodo de la especie Charonia Lampas (Trithon Nodiferum), del género Caronia, familia Ranellidae, el primero, presenta una forma cilíndrica casi perfecta y una perforación de forma circular y sección cilíndrica longitudinal, y el segundo muestra morfología cilíndrica, ligeramente convexa en la cara y en las bases, y se diferencia de los demás ejemplares de esta categoría de adornos por su perforación, que presenta forma circular y sección cilíndrica trasversal al eje mayor. No hemos considerado, aunque de morfología cilíndrica, los elementos encontrados en los Estratos III y II de Padru Jossu, Sanluri, elaborados con el exoesqueleto de un escafópodo, del género Antalis, de la familia Dentaliidae, puesto que los hemos incluido en el grupo de las cuentas de concha entera, ya que que conservan la forma natural de la concha, y presentan 
una perforación natural (Ugas, 1998b, 267, Fig. 7, 269, Fig. 9). Veinte elementos del tipo en roca (caliza negra) (subgrupo II), han sido hallados en la tumba I de Anghelu Ruju, probablemente pertenecientes a un mismo collar (Taramelli, 1904, 322), y un conjunto de doce en la tumba XXX de la misma necrópolis. En la misma sepultura fueron descubiertos seis elementos que forman parte de un mismo collar (AA.VV., 1998, 96; Taramelli, 1909a, 504-515), y un elemento pertenece al collar más largo de los del Estrato II de Padru Jossu en Sanluri, (AA.VV., 1998, 327). Hay un único ejemplar en mineral (subgrupo III), probablemente en serpentina de color verde oscuro proveniente de la tumba de Is Calitas Soleminis (Manunza et alii, 2005, p. 175; Sanna, 2005, 179-180), perteneciente a un periodo más reciente.

\subsection{CUentas EN «OLIVA»}

Las cuentas en «oliva» (aceituna), conocidas también, como ovoides, en forma de barril, tonel o tonelete, presentan morfología oval, con el cuerpo más o menos compacto, y las extremidades planas o redondeadas, una perforación central circular o ligeramente ovalada y sección cilíndrica, en sentido longitudinal a su eje máximo.

Se han estudiado las cuentas en «oliva» localizadas en once yacimientos para un total de cuarenta y nueve piezas, obtenidas trabajando diferentes materiales, hueso, concha, plata, roca y mineral y un ejemplar realizado en un material que no hemos podido analizar, y que E. Contu, interpreta como un hueso de aceituna o de baya silvestre (Contu, 1955, 37) procedente de la Tumba I de Ponte Secco, Porto Torres.

Estas cuentas, que alcanzan medidas entre los $0,7 \mathrm{y}$ $1,9 \mathrm{~cm}$ de longitud, los 0,7 y $0,9 \mathrm{~cm}$ de diámetro, y los 0,1 y $1,6 \mathrm{~cm}$ de anchura, aparecen desde las fases iniciales hasta las finales del campaniforme de Cerdeña y están documentadas en toda el área estudiada, aunque la mayor concentración, catorce ejemplares, se encuentra en la tumba en fosa de Is Calitas, en Soleminis que puede ser fechada en el Bronce Antiguo Inicial.

En roca sedimentaria (subgrupo I), caliza de color negro, hay cinco cuentas, dos halladas en las tumbas I y XIII de la necrópolis de Anghelu Ruju y dos cuentas perteneciente a un collar de la tumba XIII de la misma necrópolis. En la misma sepultura, en roca volcánica, piedra pómez, apareció también otro ornamento fragmentario (Taramelli, 1904, 301-323; 1909a, 413431). En mineral (subgrupo II) hay dos cuentas en barril, una en calcedonia de color amarillo verdoso, del dolmen de Motorra, Dorgali (Lilliu, 1968, 81) y un ejemplar en un mineral de color verde, probablemente talco (esteatita), perteneciente al collar de la tumba XXX de Anghelu Ruju (Taramelli, 1909a, 416423). Preciosas son las pequeñas cuentas en oliva, en metal, concretamente en plata (subgrupo III), cuatro provienen del estrato III de la tumba de Padru Jossu en
Sanluri (Ugas, 1998b, 266-268), dos de la tumba XIII y dos de la XXbis de la necrópolis de Anghelu Ruju, Alghero (Taramelli, 1909a, 413-431, 467-486). Sólo tres cuentas están realizadas en material malacológico (subgrupo IV). Una cuenta hallada en el estrato III de Padru Jossu, Sanluri, fue elaborada con el exoesqueleto de un bivalvo del género Spondylus y de la familia Spondylidae (AA.VV., 1998, 322-323; Ugas, 1998b, 266-268), otra (Manunza et alii, 2005, 174) de Is Calitas Soleminis, fue realizada con el exoesqueleto de un bivalvo seguramente de la familia de Glycymeridae o Cardiidae y un último ornamento de la Tumba I de Santu Pedru, Alghero, (Contu, 1964, 65-66 y 187-188) fue obtenido trabajando el exoesqueleto de un gasterópodo de la especie Charonia Lampas (Trithon Nodiferum), del género Charonia, familia Ranellidae. De hueso trabajado (subgrupo V) es una cuenta del Estrato III de Padru Jossu, Sanluri, (Ugas, 1998b, 266-268), trece elementos (Manunza et alii, 2005, 174) de Is Calitas, Soleminis y ocho de Bingia 'e Monti, Gonnostramatza, seguramente, estos últimos, pertenecientes a un mismo collar (Atzeni, 1998b, 254-260; AA.VV., 1998, 298-315). De morfología muy irregular son los tres ornamentos de Cuguttu, Alghero (Taramelli, 1909b, 102), particularmente el de tamaño mayor, con cuerpo cilíndrico troncocónico y los márgenes convexos. Una cuenta en forma de barril se conserva en uno de los collares de Capo S'Elia, Cagliari (Atzeni, 2003, lám. 1. 2) y otra en un collar de la Colección Doneddu, conservada en el Museo Villa Sulcis de Carbonia (AA.VV., 1988, 61). Destacamos tres elementos en hueso, los ejemplares de la Colección Doneddu (Fig. 6. 9-10), que lucen una decoración incisa en líneas paralelas al eje del objeto, y una pequeña cuenta, con cuerpo estilizado, de la Colección Erriu, del Museo Archeologico Nazionale de Cagliari, también con una decoración incisa de líneas paralelas, que a diferencia de las anteriores, son transversales al eje mayor y se localizan en las dos extremidades de la pieza en cuatro bandas. Tenemos, todavía que puntualizar que estos objetos, pertenecientes a colecciones privadas, no se pueden atribuir con exactitud a la fase campaniforme. Este último ornamento encuentra profundas afinidades morfológicas con una pieza hallada en la gruta Taní de Carbonia, decorada en las extremidades con sutiles incisiones, aunque ésta tenga una perforación trasversal al eje mayor y no paralela, de la cual se desconoce la pertenencia cronológica y cultural (Ferrarese Ceruti, 1997, 546).

Este grupo morfológico, conocido en los contextos europeos, se difundió en Cerdeña, ya desde el Neolítico, como ejemplifican las cuentas de los collares en talco (esteatita) de los círculos tumbales de Li Muri de Arzaquena (Contu, 2006, 210), aunque algunos investigadores, piensan que la cuentas en forma de barril en hueso, son una simplificación de las cuentas con apéndices laterales o en alamar, derivadas a su vez de los botones con apéndices laterales o en alamar, o que podían ser una continuación del filón del eneolítico 


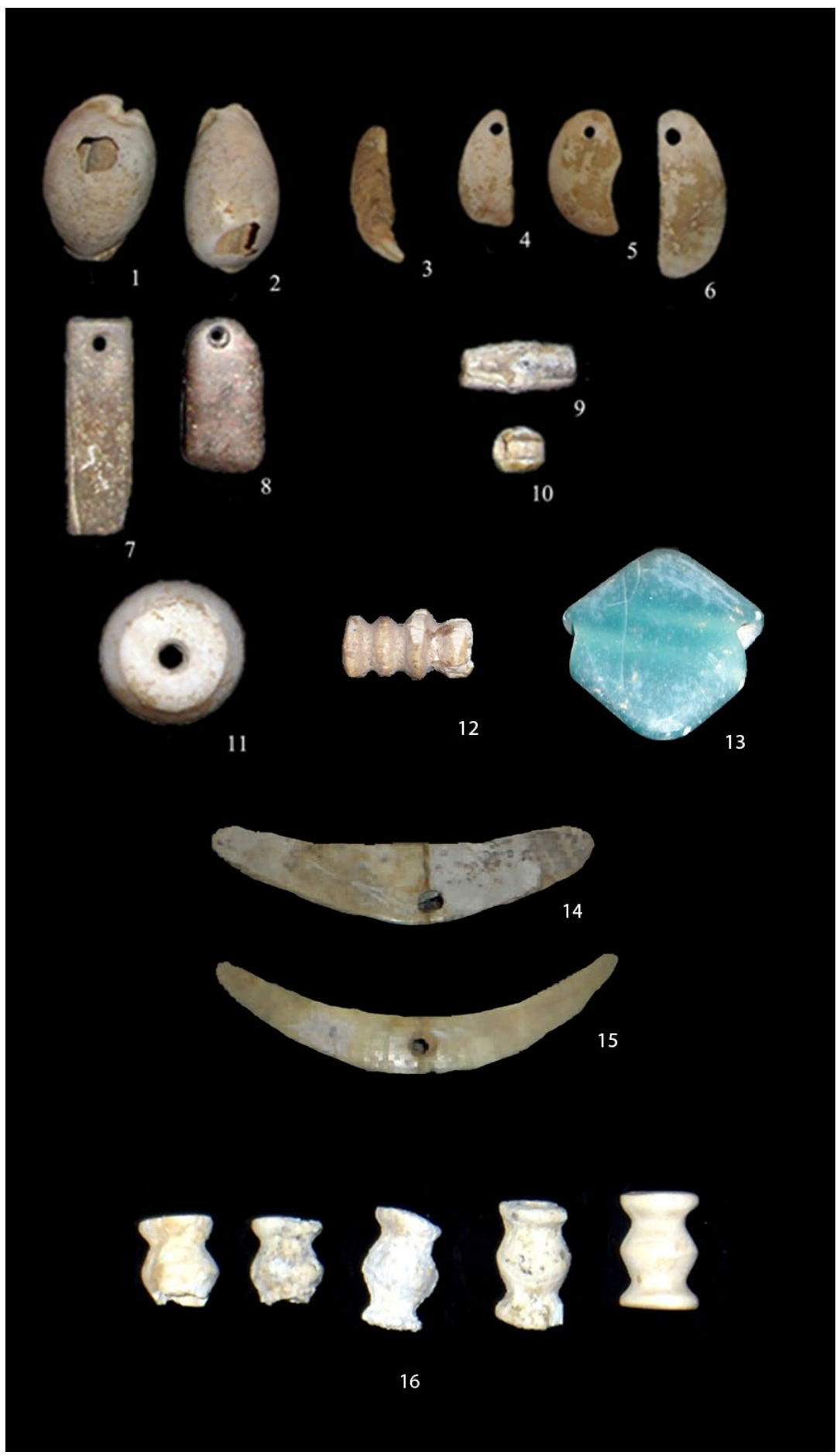

Figura 6: 1.Colgante de Cypraea; 2. Colgante de Cypraea; 3. Diente de animal; 4. Colgante subtriangular; 5.6. Colgantes subelíptico; 7. Colgante rectangular; 8. Colgante en forma de hacha; 9.10. Cuentas en forma de barril; 11. Cuenta troncocónica; (Locci Santus. San Giovanni Suergiu/ (Colección Doneddu, Carbonia); 12. Cuenta con decoración en glóbulos (Coleción Pispisa, Carbonia); 13. Colgante o cuenta en forma romboidal (Padru Jossu, Sanluri); 14.15. Colgantes en forma de creciente lunar (Padru Jossu, Sanluri); 16. Cuentas con apéndices laterales o en alamar (Padru Jossu, Sanluri).

local (Manunza et alii, 2005, 146). De todas formas estas piezas aparecen también hasta el periodo nuragico, y un ejemplo son las cuentas recompuestas en un collar conservado en el Museo G.A. Sanna de Sassari y anteriormente perteneciente a la Collección Dessí (Fois, 2000, 120).

\subsection{CUENTAS CON APÉNDICES LATERALES O A GLOBULOS}

Las cuentas con apéndices laterales o en alamar, son elementos, así denominados, por su fuerte similitud morfológica con los botones con apéndices laterales o en alamar (Pau, 2012), y hay quien las considera una 
evolución de estos últimos (Manunza et alii, 2005, 146). Se conocen también como cuentas en glóbulos porque presentan, uno o dos glóbulos centrales y dos apéndices laterales rectangulares o trapezoidales (con los márgenes redondeados) o semicirculares. En algunos elementos los apéndices laterales están casi completamente integrados en el cuerpo, y el ornamento ofrece una morfología casi cilíndrica. Presentan perforación rectilínea pasante, paralela a su eje máximo, de sección cilíndrica, cónica o bicónica.

No todos los investigadores consideran estos ornamentos como cuentas, algunos, los referencian como colgantes y otros los insertan en la categoría de los botones, aunque consideramos que su morfología y en particular su perforación, permite un uso más eficaz como cuentas, y además destacamos la similitud morfológica entre estas piezas y los elementos en hueso con decoraciones globulares, interpretados normalmente, como alfileres o cabezas de alfileres.

Las cuentas con apéndices laterales se configuran en escasas materias primas, hueso y marfil (subgrupo I) y en menor mesura en mineral, talco (esteatita) de color verde azulado (subgrupo II), y presentan un tamaño variable (longitud 1,5/3,7 cm; anchura 0,6/1,45 $\mathrm{cm}$; diámetro $0,1 / 0,8 \mathrm{~cm})$.

El subgrupo I comprende doce cuentas en hueso y/o marfil (subgrupo I), que han sido ordenadas en dos tipologías diferentes. El primer tipo (tipo I) constituido por nueve elementos, comprende las piezas con cuerpo circular o elíptico (un glóbulo central), y dos alitas laterales, los cinco pequeños elementos del estrato II de Padru Jossu, Sanluri (Fig. 6. 16) (AA.VV., 1998, 328), las dos cuentas de la necrópolis de Anghelu Ruju, (tumba III, tumba XIII) (Taramelli, 1904, 323-335; 1909a, 413-431), de incierta cronología, y dos elementos con morfología casi cilíndrica de la tumba de Is Calitas Soleminis (Manunza et alii, 2005, 150, 176). Al tipo II, con dos glóbulos centrales, pertenecen tres cuentas. Una pieza de la Colección Pispisa de Carbonia, que presenta dos glóbulos circulares centrales y dos apéndices semicirculares (Fig. 6. 12) (AA.VV., 1988, 65-66.), aunque no podemos, declarar con seguridad su pertenencia al periodo campaniforme, ignorando su contexto arqueológico. Esta cuenta presenta fuertes analogías formales con un pequeño elemento, de problemática interpretación cronológica, hallado en la gruta Taní de Carbonia, aunque este fue obtenido trabajando una roca (Ferrarese Ceruti, 1997, 546). Otros dos elementos, uno del estrato III (podría ser intrusivo) y otro del estrato II de Padru Jossu, Sanluri, con dos glóbulos elípticos centrales y dos apéndices trapezoidales con los ángulos redondeados (AA.VV., 1998, 323, 329; Ugas, 1998b, 268, 273), se incluyen en este tipo. Pertenecen al subgrupo II tres cuentas en mineral (talco-esteatita) del collar de la tumba XXX de la necrópolis de Anghelu Ruju, Alghero, con cuerpo central elíptico y alitas rectangulares, que vienen colocadas en el Eneolítico Final (AA.VV., 1998, 296). En este subgrupo por lo tanto tenemos piezas del tipo I con un solo glóbulo central.

Podremos sugerir que las cuentas con apéndices laterales estilizan su cuerpo llegando a una morfología casi cilíndrica (las dos cuentas de Is Calitas, Soleminis), además podemos colocar estas piezas entre las fases más recientes del Eneolítico Final y los inicios del Bronce Antiguo, coincidiendo con los investigadores que consideran estas piezas como un trait d'union entre los elementos campaniformes más tardíos y los más antiguos de Bonnanaro (Manunza et alii, 2005, 146).

\subsection{Cuentas DE CONCHA ENTERA}

Las cuentas de concha entera, son ornamentos obtenidos conservando la morfología anatómica natural del caparazón de moluscos marinos, y aprovechando su perforación natural.

Encontramos, dos elementos en Padru Jossu, Sanluri (estrato II y III) elaborados con el exoesqueleto de un escafópodo, del género Antalis, de la familia Dentaliidae, por lo tanto uno perteneciente al Campaniforme A y el otro al Campaniforme B de G. Ugas (1998b, 267, Fig. 7, 269, Fig. 9).

Las cuentas de escafópodo, se conocen en Cerdeña ya desde el Neolítico, pudiéndose citar los elementos en Dentalium de la Grotta Rifugio de Oliena (Contu, 2006, 85), o los ornamentos eneolíticos del collar encontrado en el yacimiento de la calle Basilicata en Cagliari (Atzeni, 2003, 23 lám. 26) de cronología Monte Claro y, por tanto, incluso posiblemente contemporáneos al fenómeno campaniforme, y los ornamentos en concha continuarán a ser utilizados hasta época nurágica (Bronce medio y reciente) (Fois, 2000, 28).

\subsection{Cuentas troncocónICAS Y BiCÓNICAS}

Las cuentas troncocónicas, aunque podría tratarse también de anillos, botones, fusaiolas o appliques para decorar alfileres, armas o instrumentos diferentes, son elementos de morfología troncocónica y sección trapezoidal, y presentan una perforación central en sentido longitudinal a su eje máximo. Los elementos examinados tenían perforación bicónica, cilíndrica o troncocónica, y habían sido elaborados con los exoesqueletos de bivalvos, de la especie Pectunculus del género Glycymeris, de la familia Glycymeridae, o probablemente de bivalvos de la familia Cardidae. Las dimensiones medias son de 1,9 y $2,8 \mathrm{~cm}$ de diámetro y 0,4 y $1 \mathrm{~cm}$ de espesor.

Este grupo de ornamentos, se documenta solo en las fases epicampaniformes; por eso algunos investigadores los consideran elementos exclusivos de la $f a-$ cies de Bonnanaro (Manunza et alii, 2005, 145). Fuera de Cerdeña recordamos, en el Bronce Antiguo, los 
elementos similares de la cultura de Polada (Barich, 1971, 121, Fig. 19, 122).

Dos cuentas troncocónicas, se conservan en uno de los collares de Capo S'Elia (Atzeni, 2003, lám. 1. 2 ), otro elemento aparece entre los ornamentos de la Colección Doneddu, de Carbonia (Fig. 6. 11), y seis cuentas decoran el collar (Atzeni, 2007, 89 lám. XIII 2) de Cuccuru Nuraxi, Settimo San Pietro, cuatro proceden de la tumba de Is Calitas, en Soleminis (Manunza et alii, 2005, 173), dos cuentas de las tumbas XVIII y XXV de la necrópolis de Anghelu Ruju, Alghero (Taramelli, 1909a, 446-451, 495-497), y un elemento de incierta atribución cronológica de la necrópolis de Su Crocifissu Mannu, Porto Torres (Ferrarese Ceruti, 1974,169).

Las cuentas bicónicas, son elementos de morfología bicónica y sección romboidal, y presentan una perforación, de forma circular y sección cilíndrica, central en sentido longitudinal a su eje máximo.

En los yacimientos campaniformes sardos examinados este grupo de adornos se encuentra sólo en dos sepulturas. Una cuenta obtenida del exoesqueleto de un bivalvo (Glycymeridae o Cardidae) aparece en uno de los collares de Bingia e' Monti, Gonnostramatza, (AA.VV., 1998a, 306) y al menos seis cuentas proceden de la tumba XXX de Anghelu Ruju, Alghero, en caliza blanca (Taramelli, 1909a, 504-517).

En realidad estas piezas por su forma y dimensiones (con un diámetro alrededor de los $3 \mathrm{~cm}$ ), pueden ser interpretados no sólo como cuentas de collar, sino también como separadores de cuentas, y ésta sería la función del elemento del collar de Bingia e' Monti (AA.VV., 1998a, 306) aunque no podemos descartar su posible uso como fusayolas.

\subsection{Cuentas EN ESPIRAL}

Son piezas formadas por barritas o hilos de cobre en espiral. Contamos sólo con cuatro elementos, tres de la tumba XXX de Anghelu Ruju, Alghero y uno con 13 giros de espiral, de Cuguttu, en Alghero (longitud 2,5 cm) (Taramelli, 1909a, 504-517; Taramelli, 1909b, 102). Por sus reducidas dimensiones descartamos su uso como anillos, pero podría tratarse de cuentas, pendientes, o elementos utilizados para decorar el pelo, en particular para bloquear las trenzas (pasadores).

Joyas en espiral, se encuentran en Europa en las áreas afectadas por el fenómeno campaniforme, y también en la cultura de los vasos cordados (Turek y Černý, 2001, 603). Ejemplos campaniformes son los anillos en espiral en oro de São Pedro do Estoril, encontrados enrollados en las falanges de los inhumados (AA.VV., 2005, 165). En España esta morfología de adornos será característica de la Cultura Argárica, utilizados como pendientes (diámetro entre los 0,4 y 4,7 cm), anillos (diámetro entre los 0,9 y $2,2 \mathrm{~cm}$ ) (Montero-Ruiz, 1992) u ornamentos para el pelo, y los de dimensiones mayores usados como brazaletes y en muchos casos hallados en posición anatómica, como demuestran elementos del ajuar de tumbas de la Cuesta del Negro (Purullena, Granada) (Torre, 1974; Contreras et alii., 1997, 143).

\subsection{CUENTA CON ALitas}

Hay un pequeño elemento, en alabastro o más probablemente en calcita, sin perforación, del estrato III, fase A de Padru Jossu, Sanluri, que según su descubridor, G. Ugas, recuerda en su morfología las «perles o pendeloque à ailettes» típicas de Francia (cuentas o colgantes con alitas) (Ugas, 1998b, 266-267), y en este caso constituiría un unicum en Cerdeña.

En el resto de Italia ornamentos pertenecientes a este grupo (en glóbulos y a cuerpo único) fueron hallados en algunos yacimientos eneolíticos del norte, en particular modo en Liguria, en algunas grutas de la Valle Argentina (Imperia), como la Arma della Grà di Marmo (Realdo, Triora), donde se encontraron 19 colgantes, en mármol o calcita (Ricci, 1988), y en la misma región en la Val Maremmola, la Tana di Armusso (Savona) (Odetti, 1987-88; 1988). En Lombardía los mismos elementos aparecieron en la Buca di Andrea di Zogno, en el Buco del Corno di Entratico, en el Bus della Scabla di Aviatico (Poggiani Keller, 1988, 409), y en una variante, en el Buco della Strega di Magreglio, mientras que en el Véneto en las Colombare de Negrar (Cocchi Genik, 1996b, 247).

Esta tipología de colgantes, está ampliamente representada en la Francia Meridional, su presencia en la Liguria y su difusión en Lombardía y Véneto, puede ser un claro indicio de los contactos entre el territorio francés y la Italia septentrional (Cocchi Genik, 1996b, 244, 247); y naturalmente si el hallazgo sardo entrara en este grupo de ornamentos, podría ser un elemento más para poder demostrar que también la isla de Cerdeña en el Eneolítico tenía relaciones con estas regiones.

\section{COLGANTES}

\subsection{Colgantes de Dientes EnTERos}

Son elementos de morfología natural (Fig. 5. 29-35; Fig. 6. 3), perforados en la raíz, trasversalmente al eje mayor, para poderlos adaptar a la suspensión. En algunos elementos se puede notar una parcial modificación morfológica.

Se han analizado colgantes obtenidos de caninos de cánidos (Canis Familiaris y Vulpes Vulpes) (subgrupo I), de cérvidos (Cervus Elaphus) (subgrupo II), bóvidos (Bovis) (subgrupo III), de oso o hipopótamo (subgrupo IV), y también dientes humanos (subgrupo V) en el estrato II de Padru Jossu, Sanluri (Lilliu, 1999, 148; Ugas, 1998b, 271). No trataremos en este apartado los colgantes, obtenidos de colmillos de 
jabalí, puesto que los hemos incluido en la categoría de los colgantes en forma de creciente lunar.

Los dientes de cánidos perforados (subgrupo I), pertenecieron a Canis Familiaris y Vulpes Vulpes, presentan forma alargada, y una extremidad puntiaguda, como pequeños cuernos, y una perforación de forma circular y sección cilíndrica, troncocónica o bicónica en la raíz. Los colgantes de dientes de cánidos se han encontrado en ocho yacimientos de los estudiados, todos lugares funerarios (Capo S'Elia en Cagliari, Colección Doneddu de Carbonia, Padru Jossu en Sanluri, Monte Luna en Senorbí, Bingia 'e Monti en Gonnostramatza, Cuguttu y Anghelu Ruju en Alghero, Su Crucifissu Mannu en Porto Torres) (AA.VV., 1988, 61; AA.VV., 1990, 69-72; AA.VV., 1998, 306; Castillo Yurrita, 1928, 121; Ferrarese Ceruti, 1974, 164; Taramelli, 1904; 1909a; 1909b; Ugas, 1982, 22; lám. XVI) y podemos precisar que se trata de un tipo de adorno utilizado por todo el periodo de desarrollo del campaniforme en Cerdeña, aunque no podemos considerarlo un elemento exclusivo de este fenómeno, siendo muy común desde el Neolítico en todo el Mediterráneo (Manunza et alii, 2005, 144) y también en las necrópolis prehistóricas de Cerdeña (Ferrarese Ceruti, 1974, 164), donde continúa a ser utilizado también en época nurágica (precisamente en el Bronce medio) con los colmillos de jabalí (Palmavera en Alghero, Punta Niedda en Portoscuso, Nuraghe Bullitas en Alghero) (Fois, 2000, 28, 29). El segundo subgrupo de colgantes (subgrupo II), se realizaba utilizando diente de ciervo (Cervus Elaphus), y con una preferencia por los atrofiados (geminación de caninos). Algunos investigadores subrayan que esta tipología ornamental, ya conocida desde momentos preneolíticos en contextos europeos, por ejemplo en los yacimientos epipaleolíticos franceses de Tèviec o Höedic (Pérez Arrondo y Lopez de Calle Cámara, 1985, 24), o en el deposito Epigravettiano de las Arene Candide en Italia (Cocchi Genik, 1996a, 229; 2009, 104-105), se atestigua en Cerdeña, a excepción de un elemento de la gruta de Sa Ucca de Su Tintirriolu de Mara, (Ferrarese Ceruti, 1974, 361), sólo desde el Bronce Antiguo inicial, cuando se sienten todavía los ecos del fenómeno campaniforme; por lo tanto, estos estudiosos indican que todos estos elementos, a excepción naturalmente del caso, citado anteriormente, de Mara, proceden de contextos Bonnanaro, y consideran este ornamento como «fósil guía» de esta cultura (Contu, 2006, 436-437; Ferrarese Ceruti, 1997, 361; Manunza, 2001, 681). M.L. Ferrarese Ceruti habla de ocho ejemplares conocidos en Cerdeña (gruta de Capo S'Elia en Cagliari, de S'Orreri en Fluminimaggiore y de la tumba de Cuccuru Nuraxi en Settimo San Pietro) (Ferrarese Ceruti, 1981, LXXIV), mientras que M.R. Manunza habla de nueve ejemplares anteriores a los diez encontrados en Is Calitas, Soleminis (Manunza et alii, 2005, 145).

En el presente trabajo se han estudiado dientes atrofiados de ciervo, de Capo S'Elia (tres), de Cuccuru Nuraxi (tres) (Ferrarese Ceruti, 1997, 361, 379 Fig.
55, 56) y de Is Calitas (diez) (Manunza et alii, 2005, 168). Presentan una morfología oval y la base abultada, y sección plano-convexa, como pequeñas gotas, y una perforación en el extremo distal de forma circular u oval, de sección cilíndrica, troncocónica o bicónica. Dos de los elementos de Capo S' Elia están fragmentados. Además hemos añadido a nuestro análisis, los colgantes de diente de ciervo (Cervus Helafus), que constituyen con los dientes de cánidos (Vulpes Vulpes), uno de los collares en marfil de Bingia 'e Monti en Gonnostramatza, que vienen fechados, según el catálogo de «Simbolo ed enigma, il bicchiere campaniforme e l'Italia nella preistoria europea del III millennio a.C.» de 1998, en el periodo comprendido entre el Eneolítico Final y el Bronce Antiguo (AA.VV., 1998, 306).

El tercer subgrupo (subgrupo III) está constituido por los colgantes obtenidos de dientes incisivos de bóvidos (Bovis Taurus), y en realidad está formado por escasos elementos, tres dientes perforados en la raíz, de la tumba hipogeico-megalítica de Bingia 'e Monti en Gonnostramatza, el primero de 3,8x1,4 $\mathrm{cm}$, el segundo $3,2 \times 0,8 \mathrm{~cm}$ y el tercero $3,3 \times 1,1 \mathrm{~cm}$, fechados entre el Eneolítico Final y el Bronce Antiguo (AA.VV., 1998, 299).

El cuarto subgrupo (subgrupo IV) está formado por los dientes perforados de oso, como los hallados en la necrópolis de Anghelu Ruju, (tumbas XIII y XVII) de dificultosa interpretación cronológica (Taramelli, 1909a, 421-422, Fig. 12), y el colgante en forma de pez del estrato II de Padru Jossu Sanluri, (en diente de oso o de hipopótamo) (Ugas, 1998b, 271) fechado en el campaniforme B de G. Ugas, con dos agujeros, uno en la raíz pasante, y un segundo en posición ortogonal en el dorso, creando una perforación en forma de «lambda» (dimensiones 5,6x1,8x1,2cm) (AA.VV., 1998, 328).

Por último señalamos, que en el Estrato II de Padru Jossu, Sanluri, G. Ugas, hipotiza que puedan pertenecer a uno de los collares, cuyos elementos se hallaron en el exterior del hipogeo cerca del nicho 1, cinco muelas humanas todavía sin perforación (Ugas, 1998b, 271), lo que sería el único caso en la Cerdeña campaniforme (subgrupo V), mientras que en épocas anteriores se señalan dientes humanos utilizados como colgantes como los hallados en sepulcro en fosa en la gruta natural de Rurèu-Alghero, asociada a objetos del neolítico reciente (Lilliu, 1999, 148).

\subsection{Colgantes EN FORMA DE CRECIENTE LUNAR}

En este grupo (colgantes en forma de creciente lunar o colgantes en forma de arco) (Fig. 6. 14-15) insertamos todos los ornamentos estudiados que presentan forma arqueada, natural o artificial, que hemos dividido en subgrupos según el soporte en el que fueron realizados, colmillos de suido (Sus Scrofa) (subgrupo I), hueso (subgrupo II), o concha (subgrupo III). 
Estos adornos, en época campaniforme son característicos de Europa Central (Salanova, 2005, 11), y se han atestiguado también en la Francia Meridional (Lemercier, 2002, 123), en Portugal, en mármol y caliza, como los ejemplares decorados de la gruta de Carenque (Sintra) y los de la tumba de Cabeço da Arruda (Torre Vedras) (Veiga Ferreira, 1966, lám. I, 119-120; III 17,18; E 65,76), y en Italia en particular en Lombardía en Ca' di Marco (Cocchi Genik, 1996b, 291), y Santa Cristina di Fiesse (Brescia) (AA.VV., 1994) y en Toscana en Pectunculus en la Gruta del Fontino, y en los yacimientos eneolíticos de la Grotta del Leone di Agnano, y de la Buca de San Antimo en Montalcino (Vigliardi, 1980, 279, 280, Fig. 10).

Este grupo de adornos, obtenidos de colmillos de suidos, es conocido en Cerdeña ya desde el Neolítico, como ejemplifican los colgantes de colmillo de jabalí con agujero para la suspensión de la Grotta Rifugio de Oliena (Contu, 2006, 85), y persistirán, con los dientes perforados de animal, hasta época nuragica (en el Bronce medio en particular), como ya hemos comentado anteriormente (Fois, 2000, 28-29). Según Ferrarese Ceruti, se podría suponer que este tipo de ornamento llegó a la isla desde las Alpes, a través de la Toscana, o directamente desde la Francia Meridional (Ferrarese Ceruti, 1997, 335); y nosotros consideramos que la presencia de este hallazgo utilizado como adorno, en esta gran área europea, es un claro testimonio de relaciones culturales y contactos entre los territorios europeos, en los cuales Cerdeña por su posición central en el Mediterráneo, tenía que haber tenido, en la Prehistoria, una función importante y esencial.

El primer subgrupo está formado por los colmillos de jabalí. Estos hallazgos aparecen en diez de los yacimientos estudiados (Capo S'Elia en Cagliari, Colección Erriu de Cagliari, Padru Jossu en Sanluri, Monte Luna en Senorbí, Is Calitas en Soleminis, Bingia e' Monti en Gonnostramatza, Colección privada de Gavoi, Anghelu Ruju y Cuguttu en Alghero, Ponte Secco en Porto Torres) (AA.VV., 1990, 69-72; AA.VV., 1998, 304, 323 y 325-328; Atzeni, 1980, 39 y 41; Contu, 1955, 27, 35 y 38; Ferrarese Ceruti, 1997, 230; Manunza et alii, 2005, 144 y 166-167; Ugas, 1998b, 271; Taramelli, 1904, 323-335; 1909b 101-103), y cubren la fase cronológica completa del campaniforme sardo. Varían en sus dimensiones con una longitud máxima de 4,2 cm e una mínima de $10,9 \mathrm{~cm}$, y un anchura entre los 0,2 y los $2,2 \mathrm{~cm}$. El colgante podía conservar la forma natural del colmillo, podía estar cortado en la raíz, o ser trabajado y reducido en lámina. Hemos dividido este subgrupo de adornos, en 3 tipos morfológicos relacionados al método de sujeción. El tipo 1 presenta perforación pasante de forma circular o ligeramente oval y sección troncocónica o cilíndrica, y por lo tanto se podía sujetar por suspensión (presente desde el Eneolítico Final hasta el Bronce Antiguo Inicial); el 2 presenta acanaladuras y se podría atar, enrollando un hilo o una cuerda (presente en la fases finales del campaniforme); el tipo 3 no presenta elementos para la sujeción. El tipo 1, podía presentar una perforación (doble agujero) localizada en uno de los lados, como en los colgantes centrales de los collares del estrato II de Padru Jossu en Sanluri, dos de los colgantes de Ponte Secco, Porto Torres, y los 4 colgantes de Bingia e' Monti en Gonnostramazta; podía presentar una única perforación central (doble agujero) como los 9 colgantes de Is Calitas, Soleminis o una única perforación central (un agujero) en los dos colgantes del estrato II de Padru Jossu en Sanluri, los dos elementos de Capo S'Elia de Cagliari o el de Cuguttu en Alghero; o podía tener una doble perforación central (doble agujero) como el colgante del estrato III de Padru Jossu, Sanluri; también podían presentar una perforación en posición central y una segunda en el ápice como el colmillo de jabalí de Bingia e' Monti en Gonnostramatza. Este tipo de adorno fue utilizado preferentemente como colgante central en los collares. El tipo 2, puede presentar acanaladuras en los dos lados y podía ser utilizado en la decoración de los brazalete (pulseras o tobilleras) más que en collares (Ugas, 1998b, 271), como el colmillo del Estrato II de Padru Jossu en Sanluri, o presentar en una sola de las extremidades dobles acanaladuras con perforación como uno de los tres colmillos de la Collección Erriu conservados en el Museo Archeologico Nazionale de Cagliari, o una perforación en el centro y en la extremidad acanaladuras como uno de los colmillos de suido (Sus Scrofa) de Is Calitas en Soleminis. Hay también colmillos sin perforación o acanaladuras (tipo 3), como los siete elementos de Bingia e' Monti en Gonnostramatza.

El segundo subgrupo está formado por colgantes en forma de arco, realizados con soporte óseo; miden entre los 0,6 y $2 \mathrm{~cm}$ de longitud, y lo 0,5 y los $8,9 \mathrm{~cm}$ de anchura. Pueden tener el cuerpo estilizado o compacto, con los márgenes cóncavo-convexos o plano-convexos y los ápices laterales puntiagudos o redondeados. Presentan única (tipo 1) o doble (tipo 2) perforación circular u oval pasante en posición central $\mathrm{o}$ en el centro del margen superior. Destaca un elemento con el margen superior decorado por una fila de puntos incisos de Bingia e' Monti Gonnostramatza (AA.VV., 1998, 301). Esta decoración es conocida en el campaniforme europeo, por ejemplo la podemos encontrar en un pectoral en plata en forma de arco de la tumba de Villafranca Veronese (AA.VV., 1994), en la Italia del Norte. Forman parte de este grupo los cuarenta y un elementos de Bingia 'e Monti, Gonnostramatza (AA.VV., 1998, 299-303), y dos colgantes de la tumba XIII de la necrópolis de Anghelu Ruju con una y dos perforaciones (Taramelli, 1909a, 413-431). Podemos también añadir un elemento hallado en la tumba III de la misma necrópolis, que no hemos podido analizar y que su descubridor describe como un «pendaglio $d$ 'osso foggiato come una difesa di cinghiale, ma tratto da altro osso o forse anche dal corno di un cervo» (Taramelli, 1904, 327). El subgrupo III está formado por colgantes obtenidos de los caparazones de conchas marinas trabajados en modo de obtener una forma de 
creciente lunar. Tres elementos en exoesqueleto de bivalvo (Glycymeridae o Cardidae), con perforación central proceden de Bingia e' Monti Gonnostramatza (AA.VV., 1998, 305) y tres colgantes probablemente de las mismas familias de conchas, de la necrópolis de Su Crucifissu Mannu, Porto Torres (Ferrarese Ceruti, 1997, 349, Fig. 146 y 149)

\subsection{Colgantes ovales}

Son piezas de morfología oval y sección cóncavoconvexa, con la base abultada que imitan la forma de los caninos atrofiados de ciervo, y presentan una perforación de forma circular y sección cilíndrica o troncocónica.

Hay solo nueve elementos (del Bronce Antiguo Inicial de Is Calitas, Soleminis, obtenidos probablemente de los exoesqueletos de bivalvos (Glycymeridae) (Manunza et alii, 2005, 145). No parecen tener paralelos con otros adornos sardos, mientras que en Italia hay hallazgos parecidos en cerámica en el Véneto en el Bronce inicial (Ferrarese Ceruti, 1997, 360), y en España hay colgantes ovales que imitan dientes de ciervos en roca, mineral, hueso y concha, desde el neolítico y el eneolítico (Barciela, 2008, 72).

\subsection{COlgantes LAMinARES EN CONCHA}

Son ornamentos obtenidos trabajando el exoesqueleto de conchas marinas (familia Cardidae, Glycymeridae, Donacidae o Tellinidae) (Fig. 5. 1-27; Fig. 6. 4-6), en la mayoría de los casos se utilizaban directamente fragmentos de conchas, que habían sido trasformadas por agentes naturales, como la abrasión marina. Presentan una morfología alargada, elíptica, o subelíptica, tal vez subtriangular, subrectangular, subtrapezoidal, subcircular, o subpoligonal, sección plana, planoconvexa o cóncavo-convexa, con una perforación excéntrica en uno de los extremos, de forma circular y sección cónica, bicónica, cilíndrica o irregular, aunque se han encontrado elementos sin perforación. Presentan dimensiones variables, longitud $1 / 3,8 \mathrm{~cm}$, anchura 0,98/1,4 cm, espesor 0,14/1,3 cm.

Este tipo de ornamento, es muy conocido en los contextos campaniformes sardos, y se encuentra en 15 de los yacimientos examinados, (Capo S'Elia, Colección Doneddu de Carbonia, Padru Jossu en Sanluri, Monte Luna en Senorbí, Cuccuru Nuraxi en Settimo San Pietro, Is Calitas en Soleminis, Bingia 'e Monti en Gonnostramatza, Colección privada de Gavoi, Anghelu Ruju, Cuguttu y Taulera en Alghero, Marinaru, Ponte Secco y Su Crocifissu Mannu en Porto Torres, S'Elighe Entosu en Usini) (AA.VV., 1988, 61; AA.VV., 1990, 69-72; Atzeni, 1998, 258; 2003, lám. I; Atzeni, 2007, 52-53; Contu, 1955; Ferrarese Ceruti, 1974, 168; 1997, 193-194 nota 184, 228 y 230; Manca, 2010, 238-239; Manunza et alii, 2005, 145; Taramelli,
1904, 1909a; 1909b; Ugas, 1998b, 269, Fig. 9), y podemos localizar estos adornos, cronológicamente durante todo el desarrollo del fenómeno campaniforme en Cerdeña.

Se trata de una tipología ornamental muy apreciada en el mundo antiguo, también en la Cerdeña prehistórica, en particular modo en la Cultura de Ozieri (Ferrarese Ceruti, 1974, 168), seguramente por la fácil accesibilidad del material, y por la rápida elaboración; en el caso de los exoesqueletos recogidos post-mortem, tal vez se podía disfrutar de una perforación natural.

\subsection{Colgantes de CONCHA ENTERA}

Los colgantes de concha entera (Fig. 5. 28), son ornamentos obtenidos conservando la morfología anatómica natural del caparazón de moluscos marinos o terrestres, y presentan una o más perforaciones intencionales, de forma circular, oval o irregular.

En los bivalvos la perforación estaba en el dorso, en posición central o excéntrica, en el ápice o en la charnela; en los gasterópodos en posición dorsal o apical; en los escafópodos se aprovechaba la perforación natural.

Este grupo de ornamento aparece en toda la secuencia campaniforme. Se utilizaron exoesqueletos de gasterópodos, del género Cypraea, de la familia $C y$ praeidae (Fig. 6. 1-2) (Capo S'Elia en Cagliari, Colección Doneddu de Carbonia, estrato II de Padru Jossu en Sanluri, tumba XIII, XXX de la necrópolis de Anghelu Ruju en Alghero) (AA.VV., 1988, 57-63; Colini, 1898, lám. XIX; Ugas, 1998b, 269, Fig. 9; Taramelli, 1909a, 413-431 y 504-517), del género Columbella, familia Columbelidae, (Colección Doneddu de Carbonia, estrato II de Padru Jossu en Sanluri, Monte Luna en Senorbí) (AA.VV., 1988, 57-63; AA.VV., 1990, 6972; Ugas, 1998b, 269, Fig. 9), del género Conus de la familia Conidae (estrato II de Padru Jossu en Sanluri) (AA.VV., 1998, 327), del género Nassa de la familia Nassaridae (Bingi 'e Monti Gonnostramatza, tumba XIII de la necrópolis de Anghelu Ruju en Alghero) (AA.VV., 1998, 306; Taramelli, 1909a, 413-431), del género Patella, familia Patellidae (Capo S'Elia en Cagliari, tumba XVII de la necrópolis de Anghelu Ruju en Alghero) (Colini, 1898, lám. XIX; Taramelli, 1909a, 442-450), del género Charonia, familia Ranellidae (tumba XIX de la necrópolis de Anghelu Ruju en Alghero) (Taramelli, 1909a, 451-460); exoesqueletos de bivalvos, del género Cerastoderma de la familia Cardiidae (Estrato II, III de Padru Jossu en Sanluri, Is Calitas en Soleminis, tumba XIII de la necrópolis de Anghelu Ruju en Alghero, Marinaru, Porto Torres, S'Elighe Entosu en Usini) (Contu, 1955, 63; Manca, 2010, 238; Manunza et alii, 2005, 174; Taramelli, 1909a, 413-431; Ugas, 1998b, 267, Fig. 7, 269, Fig. 9) y del género Glycymeris, de la familia Glycymerididae (Ponte Secco y Su Crucifissu Mannu en Porto Torres) (Contu, 1955, lám. Ib; Ferrarese Ceruti, 1974, 169). 
Además hay que añadir las cuentas realizadas con el caparazón de caracoles terrestres, halladas en el estrato II de Padru Jossu en Sanluri (Ugas, 1998b, 267, Fig. 7; 269, Fig. 9).

Los colgantes de concha perforada, se conocen en Cerdeña ya desde el Neolítico, pudiéndose citar los elementos neolíticos obtenidos de exoesqueletos de Columbella Rustica de la Grotta Rifugio de Oliena (Contu, 2006, 85), o los ornamentos eneolíticos recogidos en el collar de la tumba en cista lítica de San Gemiliano di Sestu (Atzeni, 2007, 335, lám. XXI), o en el collar encontrado en el yacimiento de la calle Basilicata en Cagliari (Atzeni, 2003, 23, lám. 26), y los ornamentos en concha continuarán a ser utilizados hasta época nurágica (Bronce medio y reciente) (Fois, 2000, 28).

Algunos colgantes, fueron realizados, utilizando no el caparazón de la concha, sino el material córneo, situado sobre el pie de un gasterópodo, el que cerraba, cuando el molusco se encontraba en su interior, herméticamente la boca de la concha (Saunders, 1991, 60). Los opérculos recogidos, seguramente en las orillas del mar, venían sucesivamente perforados, y utilizados como ornamentos. Opérculos del gasterópodo Astraea Rugosa (Turbo Rugosus) de la familia Turbinidae, vienen utilizados como colgantes en uno de los collares de Capo S'Elia, Cagliari (Atzeni, 2003, lám. I), otros dos elementos fueron hallados respectivamente, en la tumba XXX de la necrópolis de Anghelu Ruju (Taramelli, 1909a, 514), y en la necrópolis de Cuguttu (Taramelli, 1909b, 102). Este grupo de colgantes, fue utilizado en Cerdeña también en épocas sucesivas, como demostraría el collar de época nuragica, de S'Iscia 'e Sas Piras, Usini, compuesto de mil novecientos nueve óperculos de Cyclostema Elegans (Fois, 2000, 27). De todas formas, no tenemos que olvidar que, también en la actualidad, los opérculos de Astraea Rugosa, llamados vulgarmente «orejillas» u «ojos de Santa Lucia» vienen recogidos y utilizados para decorar joyas, collares, anillos, brazaletes, alfileres o pendientes.

\subsection{Colgantes en FORMA DE HACHA}

Son aquellas piezas de morfología trapezoidal o subtrapezoidal (Fig. 6. 8), con los márgenes redondeados, sección plana, o en algún caso ligeramente cóncavoconvexa y con el corte rectilíneo. Presentan dimensiones reducidas, entre los 0,7 y $3,9 \mathrm{~cm}$ de longitud, los 0,5 y $1,5 \mathrm{~cm}$ de espesor, y un anchura entre los $1 \mathrm{y}$ $2,9 \mathrm{~cm}$ en la base, y 0,6 y $2,2 \mathrm{~cm}$ en la extremidad superior.

Además de dividir este grupo de cuentas en subgrupos en relación al material utilizado para su elaboración, hemos también señalado la presencia en Cerdeña de tres variantes tipológicas: elementos con una perforación en el extremo superior, de forma circular, troncocónica y sección bicónica, o cilíndrica, (la tipología más abundante) (tipo 1), con dos perforaciones de forma circular y sección cilíndrica (tipo 2), sin perforación (tipo 3).

El primer subgrupo está constituido por elementos en roca (subgrupo I) metamórfica con un colgante en cuarcita de la tumba III y un ornamento en roca sedimentaria (jaspe) de la tumba XVIII, de la necrópolis de Anghelu Ruju, Alghero, los dos elementos presentan una única perforación. De la tumba XIII, de la misma necrópolis, proviene un colgante en roca metamórfica (esquisto), con una doble perforación en el margen superior, (Taramelli, 1904, 323-336; 1909a, 413-431 y 446-451), que encuentra fuertes parecidos con los elementos malteses (AA.VV., 2002, 72; Sultana, 2006, 14, 33; Trump, 2008, 213). En mineral de color verde claro, talco (esteatita) (subgrupo II) hay una pequeña hacha que proviene de Cuguttu, Alghero (Taramelli, 1909b, 103, Fig. 2) y cuatro colgantes de Su Crucifissu Mannu, Porto Torres (Ferrarese Ceruti, 1974, 145-150; 1997, 349), y todos los ejemplares presentan una única perforación pasante en el extremo superior. En piedra indefinida, encontramos un colgante de la Colección Doneddu de Carbonia, y otro de la tumba XXX de la necrópolis de Anghelu Ruju (Taramelli, 1909a, 504-517), y también dos elementos de la tumba XVII, de la misma necrópolis que no presentan perforación (Taramelli, 1909a, 442-446). El tercer subgrupo de colgantes en forma de hacha comprende los elementos en material malacológico (subgrupo III), como el ornamento de Is Calitias Soleminis obtenido del exoesqueleto de un bivalvo de la especie Pectunculus, género Glycymeris, familia Glycymeridae, con única perforación pasante, más tardío, perteneciente ya al Bronce Antiguo (Manunza et alii, 2005, 145 y 170). Incierta es la atribución al campaniforme de tres elementos, dos colgantes en forma de hacha, hallados en el hipogeo de Sant'Iroxi, Decimoputzu, uno en roca de color verde (probablemente caliza) (Ugas, 1990, lám. XXVI), y el segundo en hueso que podrían pertenecer a la facies de S'Iroxi y un pequeño elemento de la tumba I de Santu Pedru, Alghero (Contu, 1964, 188), en concha o hueso, que podría pertenecer a época anterior (Neolítico Reciente).

Estos colgantes, que reproducen en miniatura la morfología de las hachas, con o sin perforación, están ampliamente atestiguados en Cerdeña desde el Neolítico (Ferrarese Ceruti, 1997, 334), y debemos citar, por su similitud morfológica con los elementos estudiados, los colgantes en piedra, de Oliena, y de Oristano, el de Bau Porcus en micaesquisto y el de Cuccuru Arenas en esquisto gris; estos dos últimos presentan decorados una cara humana estilizada, a doble arco con dos puntos por ojos el primero y una «protome taurina» el segundo (Contu, 2006, 208; Ferrarese Ceruti, 1974, 146-148). Se puede encontrar todavía algún colgante-hacha en plena época nuragica (Contu, 2006, 373; Fois, 2000, 37). Fuera de la Cerdeña, recordamos la presencia de colgantes parecidos en los estratos más antiguos de Troya (Contu, 1964, 188), y en Malta, los colgantes en piedra verde de forma de hacha 
de Hal Saflieni (AA.VV., 2002, 72; Sultana, 2006, 14, 33; Trump, 2008, 213). En Italia, indicamos a título de ejemplo, los colgantes sicilianos de la necrópolis de Uditore, Conca d'Oro (Cassano y Manfredini, 1975, 197, Fig. 29), de Caccamo, Termini Imerese (Bovio Marconi, 1944, 111, Fig. 41), y de las Caverne de Villafrati (Bovio Marconi, 1944, 88-97) en Palermo, y los de la necrópolis de Marcita, Castelvetrano (Tusa et alii, 1997, 46), y de la gruta de Torrebigini, Partanna, en Trapani (Tusa, 1998, 215, Fig. 2).

\subsection{Colgantes Rectangulares}

Son piezas que presentan una morfología rectangular (Fig. 6. 7), con las aristas ligeramente redondeadas, sección plana y perforación circular, en uno de los lados cortos, con sección cilíndrica o bicónica.

Este grupo de adornos es escaso en ejemplares. Tenemos cuatro elementos en piedra, no identificada, con dimensiones entre los 1 y $3,8 \mathrm{~cm}$ de longitud, y los 1 y $1,5 \mathrm{~cm}$ de anchura, uno de la colección Doneddu, de Carbonia, y otro de la tumba III de Anghelu Ruju, los dos de incierta atribución campaniforme, otro probable colgante de morfología muy irregular, de Is Calitas, Soleminis, del Bronce antiguo (Manunza et alii, 2005, 146 y 175), y, finalmente, un colgante de Bingia e' Monti, Gonnostramatza. Además hay un elemento de grandes dimensiones (longitud 7,5 $\mathrm{cm}$, anchura 4 $\mathrm{cm}$ ), en esquisto (roca metamórfica) de la tumba XXV de Anghelu Ruju, que para A. Taramelli recuerda los colgantes de Portugal «che alcune volte sono di grandi dimensioni e varia decorazione graffita» (Taramelli, 1909a, 496), aunque las placas en esquisto portuguesas son, por norma, de dimensiones mayores, como se puede observar de los elementos de Monte da Barca, Coruche (Gonçalves, 2011).

\subsection{Colgantes ROMBoidales}

Tenemos un único ejemplar de colgante o cuenta romboidal (Fig. 6. 13), procedente del estrato III de Padru Jossu, Sanluri, (Campaniforme A de Ugas) (Ugas, 1998b, 263) realizado en un mineral de color verde azulado, jadeíta, calaíta o talco (esteatita). Bien pulimentado, presenta morfología romboidal con las aristas redondeadas, perfil ictiforme, sección elíptica aplanada, con perforación a doble agujero en forma de «lambda» (longitud 1,9cm; anchura 2,6 cm) (Ugas, 1982, 22).

Lo interesante de esta pieza además del soporte, piedra verde, la misma utilizada para cuentas con apéndices laterales y colgantes-hacha, es seguramente la perforación que recuerda la del colgante obtenido de diente de grande mamífero, en forma de pez del estrato II del mismo hipogeo (Campaniforme B de Ugas) (Ugas, 1998b, 263). Para el descubridor de este extraordinario yacimiento, los dos hallazgos podían ser productos de importación, y se sugiere un origen africano, «nel momento in cui l'Egitto si avviava alla fine del Medio Regno con la XII dinastía (1991-1786 a.C) prima di essere travolto dagli Hyksos» (Ugas, 1998b, 271). Esta hipótesis sería comprobada por la presencia del mismo tipo de perforación «il est percé, sur une face, au milieu du reflement central, de deux trous, qui convergent, en une seule ouverture sur l'autre face» (Vandier, 1952, 404) en el único botón o colgante con apéndices laterales hallado en Nagada, en Egipto, perteneciente a la serie 19L del esquema de los colgantes con apéndices laterales de O. Cornaggia Castiglioni, G. Calegari, (Cornaggia Castiglioni, Calegari, 1980, 231, Fig. 1, 234, Fig. 2.1., 236). G. Ugas, además pone en duda la datación en el Gerzeano, de este ornamento egipcio, porque fue descubierto en un contexto no claramente definido, y esto lo llevaría a considerar este hallazgo, teniendo en cuenta las analogías formales con elementos europeos más evolucionados, como un producto de imitación o de importación europea occidental, llegado a Egipto por cambios comerciales que afectarían África Septentrional, Cerdeña y Sicilia Occidental, a través de la relaciones con esta última (Ugas, 1998b, 272). En cualquier caso hemos visto que muchos de los tipos de adornos tienen un amplio desarrollo espacio-temporal.

\subsection{COLGANTES EN FORMA DE CORAZÓN}

Son colgantes que presentan un cuerpo semicircular, y un apéndice que facilita la suspensión, de forma cuadrangular con dos acanaladuras y perforación central. La forma combinada del cuerpo y del apéndice, es la de un pequeño corazón. Se conocen sólo cuatro elementos, en hueso, tres piezas del estrato III de Padru Jossu, (AA.VV., 1998b, 321), y un elemento similar de Bingia 'e Monti, Gonnostramatza, (AA.VV., 1998, 305). Miden entre los 1 y $1,4 \mathrm{~cm}$ de longitud, 0,7 y 1 $\mathrm{cm}$ de anchura, y los 0,5 y $0,7 \mathrm{~cm}$ de espesor.

\subsection{Colgantes Globulares O PlanOS CON APÉNDI- CES PARA LA SUSPENSIÓN}

Los colgantes globulares presentan un cuerpo de forma globular y un elemento para la suspensión en la parte superior, de forma rectangular con una perforación de forma alargada. Se conservan sólo dos elementos, un colgante en talco (esteatita) de color verde, de Bingia e' Monti, Gonnostramatza, (longitud 1,8 cm; anchura $1,3 \mathrm{~cm}$ ) (AA.VV., 1998, 304), y otro pequeño elemento, en hueso de la Tumba III de la necrópolis de Anghelu Ruju (longitud $2 \mathrm{~cm}$ ) (Taramelli, 1904, 323-335).

Los colgantes que se han denominado como planos presentan una forma circular o subelíptica y sección plana con un diámetro entre los 2,1 y los $2 \mathrm{~cm}$, y un pequeño apéndice rectangular con los ángulos redondeados y perforación perpendicular al eje del objeto. 
Tenemos dos elementos, el primero en piedra verde azulada (probablemente talco-esteatita) que es el colgante central del collar de la tumba XXX de la necrópolis de Anghelu Ruju (AA.VV., 1998, 296), mientras el segundo con cuerpo perfectamente circular, es el elemento central en marfil de uno de los collares del estrato II de Padru Jossu, Sanluri (Ugas, 2005, 205). Este último elemento está decorado con veintiocho círculos con punto central «occhi di dado», trece incisiones en una cara y quince en la otra. Esta misma decoración se encuentra también en un colgante procedente del poblado de Palazzu, en Samassi (Ferrarese Ceruti, 1997, 477). Se trata de una decoración que se repite en la Prehistoria y Protohistoria de Cerdeña; en la misma época campaniforme los «occhi di dado» decoraban los botones con apéndices laterales (Pau, 2012) y la custodia en marfil del brassard de la tumba XIII de Anghelu Ruju (Ferrarese Ceruti, 1981, 332, Fig. 136; Ugas, 2005, 205; Taramelli, 1909a, 423), y como veremos, más adelante, el botón de la tumba III de Su Crocifissu Mannu, Porto Torres (Contu, 2006, 370). Además el mismo motivo decorativo aparecerá en Cerdeña, durante época nurágica, en las navajas de afeitar en hoja cuadrangular o lunada de la Nurra, y de Laérru o Cuglieri (Lilliu, 1988, 420-421), y en cerámicas, como por ejemplo la decoración en el asa de una jarra askoide del nuraghe la Prisciona de Arzachena (Contu, 2006, 679). Esta decoración es conocida también en las demás regiones italianas, por ejemplo, en época campaniforme, aparece en el peine de la necrópolis de Marcita, Castelvetrano en Trapani con filas paralelas de círculos con punto central en un esquema casi en zig-zag (Tusa et alii, 1997, 53) y en la cultura de Polada podemos citar uno de los anillos o fusayolas de la Torbiera de Polada (Brescia) (Barich, 1971, 121, Fig. 19 y 122), y el mismo motivo decora el más tardío disco de ámbar de la Terramara di Poviglio, Villaggio Grande (Bellintani, 2010, 143). La decoración en «occhi di dado» es conocida, también, en objetos de tumbas eneolíticas de España (Taramelli, 1909a, 426), y aparece todavía en el Talayótico de Mallorca, en una cuenta o botón conservado en el Museo Arqueológico de Barcelona, y en los discos circulares con perforaciones laterales, encontrados en la Cueva de Es Càrritx, en Menorca que inicialmente fueron interpretados como colgantes, pero gracias al afortunado depósito de la sala 5 en perfecto estado de conservación fue posible conocer su verdadero uso, se trataría de tapaderas de receptáculos hechos de madera o cuerna (Lull et alii, 2006, 37).

\subsection{Fibulas-COLGANTES Y ANILLOS-COLGANTES}

Hay un ejemplar en hueso de morfología elíptica, sección plana, con doble perforación, que se ha denominado como «fibula-colgante», hallado en el estrato II de Padru Jossu en Sanluri. Lo hemos aislado en uno único grupo porque pensamos que podía tener una función diferente a la de un simple colgante, ya podría tratarse de una fíbula por el fijado del hilo (Ugas, 1998b, 272), o de un separador de hilos de collar.

Los anillos colgantes son piezas de morfología anular, que por sus dimensiones no podían ser anillos ni tampoco brazaletes. Podría tratarse de colgantes o anillos para el pelo. En caliza blanca (subgrupo I) tenemos el ornamento de la tumba XIII de Anghelu Ruju, Alghero (diámetro 7,5 cm) (Taramelli, 1909a, 375, Fig. 12), y los de la necrópolis de Su Crucifissu Mannu (diámetro alrededor de los 4,2 cm) (Ferrarese Ceruti, 1974, 146-151); en metal (subgrupo II) recordamos el elemento en cobre o bronce, curvado con los márgenes abiertos, de morfología elíptica, de la tumba XVIII (diámetro 5,1 cm) de Anghelu Ruju (Taramelli, 1909a, 446-451), los dos pequeños elementos en lámina de cobre de morfología circular y subelíptica con el diámetro de 0,4 cm de Cuguttu, Alghero (Taramelli, 1909b, 437), y un anillo en plata de 1,5 cm de diámetro de la tumba XVIII de Anghelu Ruju (Taramelli, 1909a, 446-451).

\section{ALGUNAS OBSERVACIONES SOBRE LOS SOPORTES}

Los materiales utilizados para la realización de cuentas y colgantes, son muy variados, hay elementos en materia dura animal (concha, hueso dentina y marfil), en minerales y rocas y algún adorno en metal.

Los hallazgos confeccionados en material macológico pertenecían a la clase de los gasterópodos (en particular de la familia Cypraeidae, Columbelidae, Conidae, Nassaridae, Patellidae, Ranellidae, Turbinidae), de los bivalvos (familia Cardidae, Donacidae, Glycymeridae, Spondylidae, Tellinidae) y de los escafópodos (familia Dentalidae). Se trata de conchas que viven en las aguas templadas del Mediterráneo, y constituían, sin duda, un recurso natural abundante en las costas de Cerdeña. En la mayoría de los casos examinados, parece que fueron recogidas post mortem en la orilla del mar, por tanto se puede suponer que la realización de los adornos en concha, fuera precedida por una fase de búsqueda y recogida del material, para después trasladarlo a un centro de trasformación. Esta operación podía haber sido realizada, por grupos especializados de individuos, o por los mismos expertos en el trabajo de la concha. El hecho de que no todos los yacimientos donde se han encontrado las conchas trabajadas estuvieran en la costa (Padru Jossu en Sanluri, Bingia e' Monti en Gonnostramatza etc.), sugiere que a la recogida seguiría, en estos casos, una segunda fase la de distribución. Se podía enviar en los centros de producción costera o la materia prima lista para ser trabajada, o ya el manufacturado confeccionado, en los dos casos hablamos de procesos de relación e intercambios entre los grupos del interior y los costeros.

Desde nuestro análisis, podemos ver, que se utilizaron frecuentemente también huesos, dientes y 
colmillos (Sus Scrofa) de animales y tal vez dientes humanos, y probablemente astado de cérvido para confeccionar cuentas y colgantes. Se trataría de materia prima local, y podemos suponer la existencia de centros de producción, o talleres, que presuponen una especialización durante época campaniforme en el trabajo de la materia ósea animal.

Aunque la posible presencia de un colgante obtenido de un diente de hipopótamo, en Padru Jossu, Sanluri, nos sugiere, el uso de material de importación, según G. Ugas, como hemos anteriormente comentado, se trataría de un colgante africano, probablemente egipcio (Ugas, 1998b, 271). En este caso podría tratarse de un elemento de prestigio (símbolo de riqueza o de identificación social), utilizado en los intercambios entre las familias más importantes (Pau, 2008, 181).

Materiales de importación serían también las cuentas y los colgantes en marfil, como también otros adornos, realizados en el mismo material, los botones (Pau, 2012), G. Lilliu, sugirió que se podría tratar de objetos procedentes de África, por el trámite andaluz-almeriense (Lilliu, 1999), aunque serían necesarios análisis microscópicos y espectroscópicos para poder identificar el origen del marfil, teniendo en cuenta los resultados obtenidos, en los últimos años, en los estudios del marfil calcolítico hallado en la Península Ibérica, en los cuales se identificó el uso de marfil de elefantes extinguidos en el Pleistoceno, de elefantes asiáticos, y de los africanos de sabana (Schuhmacher et alii, 2009).

Un gran número de cuentas y colgantes, se elaboraron trabajando material lítico. Las rocas utilizadas eran las metamórficas (esquisto, micaeesquisto, cuarcita, y pizarra), las sedimentarias (caliza y jaspe), y la magmáticas (piedra pómez). Se trata de materiales locales (AA.VV., 2007; Fadda, 1989), a excepción de la pizarra por la cual tendremos que considerar un origen foráneo, porque, en sentido estricto, no está presente en suelo sardo, aunque muchas veces, se suele confundir con las filitas (Fois, 2000, 35).

Entre los minerales se han podido identificar la calcedonia, la serpentina, la calcita, el cuarzo y el talco (esteatita). Todos estos minerales se encuentran en suelo sardo. El cuarzo, óxido de silicio, es muy común, se encuentra en Abbagadda cerca de Samugheo, en Acqua Bona en el Arburense, en Acquaresi y en Arenas en el Iglesiente, en Asuni, en Baccu Locci (Quirra), en Barbusi en el Sulcis, en Barega en el Iglesiente, en Barraxiuta de Domusnovas, en Bau Arenas de Terteniae y en otras muchas localidades; la calcedonia, variedad de cuarzo, en Abbagadda cerca de Samugheo, en Arenas en el Iglesiente, en Baccu Arrodas cerca de Muravera; la serpentina, mineral del grupo de la caolinita de color verde oscuro, en Cerdeña se encuentra en Orani. La calcita, carbonato de calcio, en la isla se encuentra en las principales minas del Iglesiente y en el Sarrabus. La esteatita, variedad de talco de color verde blanco, se encuentra en Orani (AA.VV., 2007, 67, 76 y 77; Fadda, 1989, 98-101, 103, 118 y 161-162).
G. Lilliu, sugiere, por la concentración elevada de elementos en esteatita en la Cerdeña Noroccidental, la presencia de una o varios talleres de producción ubicadas en esta área, utilizando la materia prima adquirida desde el interior de la isla, de los mineros de las montañas de Gonari (Orani, Sarule) (Lilliu, 1988, p. 169).

Desde nuestra análisis parece que también el colgante romboidal de Padru Jossu en Sanluri (Ugas, 1998b, 271), había sido realizado en talco verde (esteatita), aunque G. Ugas presente diferentes propuestas (jadeíta, calaíta o talco) (Ugas, 1998b, 271). Además este autor sugiere que esta pieza tipológicamente recuerda las joyas exóticas, presentando la misma perforación en forma de «lambda», del colgante obtenido de un diente de hipopótamo, remarcando la posibilidad de contactos y cambios de materiales de prestigio entre las elites mediterráneas (Pau, 2008).

Además no podemos descartar el origen foráneo de los otros adornos en materia lítica, aunque sean realizados con materiales conocidos en ámbito local, teniendo en cuenta que muchas rocas y minerales que aparecen en el suelo sardo, están presentes también en las regiones limítrofes del mediterráneo.

Algunos de los adornos estudiados se realizaron en metal, cobre o en aleaciones del cobre y en plata.

Ha sido dificultoso, poder distinguir, si los ornamentos campaniformes y epicampaniformes, fueron realizados en cobre, cobre arsenical, o bronce, no habiéndose podido realizar un análisis químico o metalográfico de las piezas, el único estudio ha sido el realizado a partir de lupa binocular y la recogida de informaciones de las fuentes bibliográficas, no siempre claras y precisas. Los minerales de cobre están muy difundidos en Cerdeña, la azurita, carbonato azul, se encuentra en Acqua Bona (Arburense), en Acquaresi y Arenas (Iglesiente), en la Argentiera (Nurra), en Baccu Lillonis (Parteolla), en Baccu Locci (Quirra), en Barisone (Torpè), en Bena de Padru (Ozieri), y también en otras localidades; la cuprita, óxido rojo de cobre, en las minas del Iglesiente, en Funtana Raminosa, y en Baccu Locci (Quirra) y en pocas otras localidades; la malaquita, carbonato verde, en el Iglesiente, en la Nurra, en Baccu Lillonis (Parteolla), en Calabona, en Funtana Raminosa; la calcopirita o pirita cuprosa, sulfuro de color amarillo latón es muy difundida en Cerdeña, en Acqua Bona en el Arburense, en Acquaresi y en Arenas en el Iglesiente, en Baccu Arrodas (Muravera), en Barisone di Torpè, en Bau Arenas (Tertenia), en Baxinieddu (Jerzu), en Bena de Padru (Ozieri), en Bruncu Cardosu (Arzana); la calcosina mineral de color gris iridiscente, se encuentra en las minas de Arenas en el Iglesiente, en Barisone (Torpè), en Bena de Padru (Ozieri); la bornita mineral de color azul violeta, se encuentra en Acquaresi y en Arenas en el Iglesiente, en Barisone (Torpè), en Bena de Padru (Ozieri); la tetraedrita en Arenas en el Iglesiente, en Argentiera, en la Nurra, en Baccu Arrodas (Muravera); y también otros minerales de cobre aparecen en la isla (AA.VV., 2007, 
63-799; Fadda, 1989, 78, 84-85, 92, 107 y 126-128). El cobre en estado nativo se encuentra en Cerdeña en las minas de Funtana Raminosa y también a Montevecchio, en las minas de Baccu Locci (Quirra) y en pocas otras localidades (AA.VV., 2007, 76). Mientras que el arsénico, mineral nativo de color negro, se encuentra en Cerdeña en las minas de Baccu Arrodas de Muravera y en las Baccu Locci (Quirra), además de combinado a diferentes minerales cupríferos ya referidos (AA.VV. 2007, 59). El estaño, tendría que ser un metal muy difícil de conseguir, ya que en Cerdeña es muy escaso, algunos autores, sugieren que el bronce era producido por la adición directa de la casiterita al cobre (Eiroa et alii, 1989, 144), aunque otros minerales aún menos frecuentes presentan mayores concentraciones de estaño. En Cerdeña la casiterita, se encuentra en las minas de Perda Majori y de Canale Serci (en pequeños cristales), en Nuraxi de Togoro y Perdu Cara, (AA.VV., 2007, 68; Fadda, 1989, 111). Es muy complicado afirmar que ya en edad campaniforme vinieran utilizados estos yacimientos con métodos de minería intensiva, aunque éstos se conocen en otras zonas para estos momentos (Blas Cortina, 2010). Podemos suponer la presencia de afloramientos de vetas de minerales, más accesibles a la hora de extraer el mineral buscado, siguiendo con trincheras las vetas más superficiales. Seguramente estos minerales se trasformaban utilizando hornos, parecidos a los usados por cocer la cerámica; los trabajos metalúrgicos podían ser ya llevados por grupos de personas especializadas, y se puede también pensar que en las áreas de mayor concentración de minerales, como podía ser el Iglesiente, podían existir centros metalúrgicos importantes.

Entre los materiales estudiados, se han podido identificar elementos en plata. La Cerdeña es rica de galena (sulfuro de plomo), (Arburense, Iglesiente, Sarrabus, Nurra, Parteolla, Ogliastra etc.) (AA.VV., 2007, 71); y hay también plata en estado nativo (Sarrabus, Acqua Bona en el Arburense, Acquaresi y Arenas en el Iglesiente, Asuni, Baccu Arrodas en Muravera etc.) (AA.VV., 2007, 65; Fadda, 1989, 78); La plata al estado puro en algunas zonas es superficial, permitiendo un abastecimiento muy productivo también sin el uso de métodos industriales (Fois, 2000, 52).

\section{CONCLUSIONES}

Desde el estudio morfológico, se ha constatado, que en todo el periodo de manifestación del fenómeno campaniforme en Cerdeña, se utilizaron joyas (colgantes y cuentas), presentes ya en el substrato cultural autóctono (cuentas discoidales, cilíndricas, en oliva, colgantes y cuentas de concha entera, colgantes laminares en concha, colgantes en forma de hacha, y en creciente lunar, colgantes geométricos). Este hecho no es extraño si tenemos en cuenta además que el campaniforme isleño se concreta en aspectos específicos del desarrollo de las culturas locales aunque en los contextos funerarios aparezca a veces como una manifestación relativamente pura y aislada.

Además, aparecen elementos, nuevos, que encuentran paralelos, con objetos hallados en el área europea de desarrollo del fenómeno campaniforme, como cuentas con apéndices laterales o en alamar, cuentas en espiral, que son los objetos que nos atestiguan la presencia del fenómeno campaniforme en la isla, desde el punto de vista de los adornos.

Hay además un grupo de objetos, que aparecen solo en las fases finales del campaniforme, o mejor, en el periodo en el cual este se híbrida en las cultura sarda del bronce Antiguo, Bonnanaro A. Son las cuentas troncocónicas, los dientes atrofiados de ciervo y los colgantes ovales.

Además tenemos que añadir un último grupo de ornamentos, que no encontramos en la tradición cultural de Cerdeña, y que contemporáneamente no caracterizan el campaniforme europeo, como la cuenta en forma de rombo de Padru Jossu, Sanluri, los colgantes en forma de corazón, y los otros elementos con apéndice de sujeción.

Desde el estudio de los ornamentos (cuentas y colgantes), hemos podido por lo tanto constatar, como el campaniforme sardo, no elimina las tradiciones estilísticas locales, continuando el uso de joyas tradicionales, aunque manifestándose en plena sintonía con las corrientes europeas, y en particular mediterráneas (aparecen adornos propiamente campaniformes), y contemporáneamente se realizan joyas singulares. El estudio de los contextos del Bronce Antiguo inicial, ha sido esencial, para poder estudiar el difuminarse de este fenómeno; ya que en esta fase continúa el uso de los elementos propiamente campaniformes, aunque ya comparecen nuevos tipos de ornamentos.

Además el uso de materias primas locales para confeccionar estas categorías de adornos, presupone la existencia en época campaniforme y epicampaniforme en Cerdeña, de centros de producción especializados, algunos de los cuales perdurarían de las épocas anteriores, como es el caso de los talleres de esteatita de Orani (Lilliu, 1988, 169), mientras que los paralelos con piezas foráneas como los típicos colgantes con alitas de la Francia meridional, o los colgantes con perforación en lambda, y también el uso del marfil de importación, testimonian el papel de trámite de la isla de Cerdeña, en relación a los contactos e intercambios en el área Mediterránea entre mediados del III Milenio cal A.C. y los inicios del II Milenio cal A.C.

\footnotetext{
Claudia Pau

Dpto. de Prehistoria y Arqueología

Fac. Filosofía y Letras

Campus Universitario de La Cartuja

Universidad de Granada

18071 Granada

claupau@ugr.es
} 


\section{BIBLIOGRAFÍA}

AA.VV., 1988: Museo Villa Sulcis, Cagliari.

AA.VV., 1990: Museo Sa domu Nosta, Cagliari.

AA.VV., 1994: Le pietre degli dei. Menhir e stele dell'etá del rame in Valcamonica e Valtellina, Bergamo.

AA.VV., 1998: Simbolo ed enigma, il bicchiere campaniforme e l'Italia nella preistoria europea del III millennio a.C., Trento.

AA.VV., 2002: Maltese prehistoric art 5000-2500 BC, Malta.

AA.VV., 2005: Cascais há 5000 anos, Cascais.

AA.VV., 2007: "Minerali in Sardegna», La Grande enciclopedia della Sardegna, Vol. 6, Editoriale La Nuova Sardegna S.p.A.

ATZENI, E., 1980: «Vornuraghenzeit» Kunst und Kultur Sardiniens vom Neolithikum bis zum Ende der Nuraghenzeit, Karlsruhe, 15-44.

ATZENI, E. 1996: «La cultura del Vaso Campaniforme e la facies di Bunnanaro nel Bronzo Antico sardo», en D. COCCHI GENIK (Ed.), L'antica età del bronzo in Italia, Atti del Congresso di Viareggio, (Viareggio, 1995), Octavo, Firenze, 397-411.

ATZENI, E., 1998a: «La Cultura del bicchiere campaniforme in Sardegna», en F. NICOLIS y E. MOTTES (Eds.), Simbolo ed enigma, il bicchiere campaniforme e l'Italia nella preistoria europea del III millennio a.C., 243-253, Trento.

ATZENI, E., 1998b: «La tomba ipogeico megalitica di Bingia 'e Monti», en F. NICOLIS y E. MOTTES (Eds.), Simbolo ed enigma, il bicchiere campaniforme e l'Italia nella preistoria europea del III millennio a.C., 254-260, Trento.

ATZENI, E., 2003: Cagliari preistorica, Cagliari.

ATZENI, E., 2007: La preistoria del golfo di Cagliari, Cagliari.

BARCIELA GONZÁLEZ, V., 2008: Adorno y simbolismo. Los adornos personales del Neolitico y Eneolítico en Villena (Alicante), Villena.

BARGE, H., 1982: Les parures du Néolithique ancien au début de l'Âge des Métaux en Languedoc, Paris.

BARICH, B.E., 1971: «Il complesso industriale della stazione di Polada sulla luce dei più recenti dati », Bullettino di Paletnologia Italiana, XXII, 80, 77-182.

BELLINTANI, P., 2010: «Ambra. Una materia prima del Nord (ma non solo)», en A. CAZZELLA y G. RECCHIA (Eds.), Ambra per Agamennone. Indigeni e Micenei tra Egeo, Ionio e Adriatico nel II millennio a. C, 139-144, Bari.

BLAS CORTINA, M.A., 2010: «La minería subterránea del cobre en Asturias: un capítulo esencial en la prehistoria reciente del norte de España», en J. A. FERNÁNDEZ TRESGUERRES (Ed.), Oro y Cobre. De la piedra al metal, 43-82, Oviedo.

BOVIO MARCONI J., 1944: «La cultura tipo Conca D’oro della Sicilia nord-occidentale», Monumenti Antichi dei Lincei, XL, 1-170.

CASSANO, S.M. y MANFREDINI, A., 1975: «Recenti ricerche nelle necropoli eneolitiche della Conca D'oro.
Scavi nella necropoli di Uditore e prospettive di inquadramento cronologico delle più antiche facies della Conca D'oro», Origini, IX, 153-223.

CASTILLO YURRITA, A., 1928: La cultura del vaso campaniforme: Origen y extensión en Europa, Barcelona.

COCCHI GENIK, D., 1996a: Manuale di preistoria, Paleolitico e Mesolitico, Vol. I, Firenze.

COCCHI GENIK, D., 1996b: Manuale di preistoria, L'etá del rame, Vol. III - 1, 2, Firenze.

COLINI, G. A., 1898: «Il sepolcretto di Remedello Sotto nel Bresciano ed il periodo Eneolitico in Italia», Bullettino di Paleotnologia Italiana, Serie III, Tomo IV, Anno XXIV, 1-17.

CONTRERAS CORTES, F., RODRIGUEZ ARIZA, M.O., CÁMARA SERRANO, J.A. y MORENO ONORATO, A., 1997: Hace 4000 años... Vida y muerte en dos poblados de la Alta Andalucía, Granada.

CONTU, E., 1955: «Ipogei eneolitici di Ponte Secco e Marinaru presso Sassari», Studi Sardi, 12-13, (1952-54), 21-80.

CONTU, E., 1964: «La tomba dei vasi Tetrapodi in loc. Santu Pedru (Alghero- Sassari) », Monumenti Antuchi dell'Accademia dei Lincei, XLVII, 1-201.

CONTU, E., 1988: «L'età del rame nell'Italia insulare. La Sardegna. Problematica ed inquadramento culturale», L'Età del Rame in Europa, Atti del Congresso Internazionale, (Viareggio, 1987), Rassegna di Archeologia 7, 441-448.

CONTU, E. 1996: «La Sardegna Problematica e inquadramento culturale», en D. COCCHI GENIK (Ed.), L'antica età del bronzo in Italia, Atti del Congresso di Viareggio, (Viareggio, 1995), 385-396, Firenze.

CONTU, E., 2006: La Sardegna preistorica e nuragica. Tomo I-II, Chiarella, Sassari.

CORNAGGIA CASTIGLIONI, O. y CALEGARI, G., 1980: «I pendagli ad alamaro dell'Eneolitico sardo», Atti della XXII Riunione Scientifica dell'Istituto Italiano di Preistoria e Protostoria nella Sardegna centro-settentrionale (Firenze, 1978), 228-245, Firenze.

EIROA, J.J., LOMBA MAURANDI, J., MARTINEZ SANCHEZ, C. y PONCE GARCIA, J., 1989: Apuntes de tipología prehistórica, Murcia.

FADDA, A. F. 1989: Sardegna pietre dure e minerali, Cagliari.

FERRARESE CERUTI, M. L., 1974: «La tomba XVI di Su Crocifissu Mannu e la cultura di Bonnanaro», Bulletino di Paletnologia Italiana, 81, (1972-74), 113-210.

FERRARESE CERUTI, M. L., 1981: «La cultura del vaso campaniforme il primo bronzo», Ichnussa, La Sardegna dalle origini all'etá classica, LV-LXV, Milano.

FERRARESE CERUTI, M.L., 1988: «L'età del rame nell'Italia insulare. La Sardegna. Il campaniforme in Sardegna», L'Età del Rame in Europa, Atti del Congresso Internazionale, (Viareggio, 1987), Rassegna di Archeologia 7, 456-460.

FERRARESE CERUTI, M.L., 1989: «L'età prenuragica. L'Eneolitico finale e la prima Età del Bronzo», Il Museo Archeologico Nazionale di Cagliari, 57-78, Cagliari. 
FERRARESE CERUTI, M. L., 1997: Archeologia della Sardegna preistorica e protostorica, Nuoro.

FOIS, A., 2000: Gli Ornamenti nuragici del Museo «G. A. Sanna» di Sassari, Piedimonte Matese.

GONÇALVES, V. S., 2011: As places de xisto gravadas (e os baculos) do sitio do Monte da Barca (Coruche), Lisboa.

LEMERCIER, O., 2002: Le Campaniforme dans le sud-est de la France. De l'Archéologie à l'Histoire du Troisième millénaire avant notre ère, Vol. I, Tesis Doctoral, Université Aix-Marseille I, Aix-en-Provence.

LILLIU G., 1968: « Il dolmen di Motorra (Dorgali-Nuoro)», Studi Sardi, 20, 74-128.

LILLIU, G., 1988: La civiltá dei sardi dal paleolítico all'etá dei nuraghi, Torino.

LILLIU, G., 1999: Arte e religione della Sardegna prenuragica, Sassari.

LULL, V., MICÓ PÈREZ, R., RHUETE HERRADA, C. y RISCH, R., 2006: Peinando la muerte: rituales de vida y muerte en la prehistoria de Menorca, Alicante.

MAGGI, R., 1990: «Rocchetta Vara (La Spezia). Loc. Pianaccia di Suvero, Officina per la produzione di oggetti in steatite dell'etá del vaso campaniforme», Bollettino di Archeologia, 1-2, 119-122.

MAGGI, R., MACPHAIL, R. I., NISBET R. y TISCORNIA I., 1987: «Pianaccia di Suvero», en P. MELLI y A. DEL LUCCHESE (Eds.), Archeologia in Liguria, III 1, Scavi e scoperte 1982-86, 23-32, Genova.

MANCA, L., 2010: «Gli oggetti d'ornamento in conchiglia», en M. G. Melis (Ed.), Usini Ricostruire il passato, una ricerca internazionale a S'Elighe Entosu, 237-249, Sassari.

MANUNZA, M. R., SANNA, I., USAI, E., BUFFA, R., CALÓ, C.M., FLORIS, G., MARINI, E., LAI, L., TAYKOT, R. H., GODDARD, E. y HOLLANDER, D., 2005: «La tomba di Bonnanaro di Is Calitas», en M. R. MANUNZA (Ed.), Cuccuru Cresia Arta. Indagini Archeologiche a Soleminis, 125-178, Cagliari.

MELIS, M. G., 2010: «La necropoli di S'Elighe Entosu e il territorio di Usini in età preistorica e protostorica», en M. G. MELIS (Ed.), Usini. Ricostruire il passato. Una ricerca internazionale a S'Elighe Entosu, 289-298, Sassari.

MONTERO RUIZ, I., 1992: Estudio arqueometalurgico en el sudeste de la Península Ibérica, Madrid.

ODETTI, G., 1987-88: «La groticella sepolcrale dell'Armusso in Val Meremola (Savona)», Rivista di Scienze Preistoriche, XLI, 315-329.

ODETTI G., 1988: «Corredi sepolcrali di una cavernetta ligure: Tana dell'Armusso (Savona)», Rassegna Archeologica, 7, 602-603.

PAU, C., 2008: «Los objetos de adorno del campaniforme sardo y su trascendencia social», Actas de las I Jornadas de Jóvenes en Investigación Arqueologica. Dialogando con la cultura material (Madrid, 2008), 175-182, Madrid.

PAU, C., 2010: «Burials in Sardinian Bell Beaker cultura», en J.A. CÁMARA SERRANO, J. A. AFONSO MARRERO y L. SPANEDDA (Eds.), Links between Megalithism and Hypogeism in Western mediterranean Europe, British Archaeological Report S2151, 121-134, Oxford.

PAU, C., 2012: «Los botones campaniformes sardos y sus analogías con la Península Ibérica y otras zonas del Mediterráneo», Saguntum, 44, 67-76.

PEREZ ARRONDO, C. L. y LOPEZ DE CALLE CÁMARA, C., 1985: «Relaciones culturales en el Eneolítico del Valle del Ebro a partir de un análisis específico sobre elementos de adorno en yacimientos riojanos», Segundo Coloquio sobre historia de la Rioja (Logroño, 1985), 19-36, Logroño.

POGGIANI KELLER R., 1988: «L'età del rame nell'Italia settentrionale.Gli aspetti sepolcrali dell'area alpina centrale», L'Età del Rame in Europa, Atti del Congresso Internazionale (Viareggio, 1987), Rassegna di Archeologia, 7, 401-411.

RICCI, M., 1988: «Le grotte sepolcrali della Valle Argentina (Imperia) con perles à ailettes», L'Età del Rame in Europa, Atti del Congresso Internazionale, (Viareggio, 1987), Rassegna di Archeologia, 7, 596-597.

SAMMARTINO, F., 1990: «Insediamenti neolitici e della prima etá dei metalli in localitá La Puzzolente (Livorno). Un'officina per la lavorazione della steatite», Rassegna di Archeologia, 9, 153-182.

SALANOVA, L., 2005: «Los orígenes del campaniforme: Descomponer, analizar, cartografiar», en M. A. ROJO, R. GARRIDO y I. GARCÍA (Eds.), El campaniforme en la Península Ibérica y su contexto europeo, 7-18, Valladolid.

SANNA, I., 2005: «Osservazioni su un vago di collana», en M. R. MANUNZA (Ed.), Cuccuru Cresia Arta. Indagini Archeologiche a Soleminis, 179-180, Cagliari.

SAUNDERS, G. D., 1991: Molluscos. Introducción a las conchas y moluscos de todo el mundo, Barcelona.

SCHUHMACHER T.X., CARDOSO J.L. y BANERJEE A., 2009: «Sourcing African ivory in Chalcolithic Portugal», Antiquity, 83, 983-997.

SULTANA, S., 2006: The national museum of archaeology. The Neolithic Period, Heritage books in associationwith, Heritage Malta.

TABORIN, Y., 2004: Langage sans parole. La parure aux temps préhistoriques, Paris.

TARAMELLI, A., 1904: «Scavi nella necropoli a grotte artificiali di Anghelu Ruyu», Notizie degli Scavi di Antichità, 301-351.

TARAMELLI, A., 1909a: «Nuovi scavi nella necropoli preistorica di Anghelu Ruyu», Monumenti Antichi dei Lincei XIX, 397-540.

TARAMELLI, A., 1909b, «Scoperte nella necropoli a grotte artificiali di Cuguttu», Notizie degli Scavi, 100-108.

TORRE PEÑA, F. de la, 1974: El ajuar de la necrópolis argárica de la Cuesta del Negro en Purullena (Grana$d a)$, Memoria de Licenciatura, Universidad de Granada, Granada.

TRUMP, D. H., 2008: Malta prehistory and temples, Midsea books Ltd.

TUREK, J. y ČERNÝ V., 2001: «Society, gender and sexual dimorphism of the Corded ware and Bell Beaker populations», en F. NICOLIS (Ed.), Bell Beakers today. 
Pottery, people, culture, symbols in prehistoric Europe. Proceedings of the International Colloquium (Riva del Garda, Trento, Italy, 1998), 601-612, Trento.

TUSA S., 1998: «La presenza del Bicchiere Campaniforme in Sicilia», Bulletino de Paletnologia Italiana, 89, 20-232.

TUSA, S., LENTINI, L., VALENTE, I. y DI SALVO, R., 1997: L'insediamento dell'età del bronzo con Bicchiere Campaniforme di Marcita, Soprintendenza per i Beni Culturali e Ambientali di Trapani, Trapani.

UGAS, G., 1982: «Padru Jossu-Tomba ipogeica ed elementi di cultura materiale delle fasi campaniforme A e B», Ricerche archeologiche nel territorio di Sanluri, Mostra grafica e fotografica (Sanluri, 1982), 19-26.

UGAS, G., 1990: «La tomba dei guerrieri di Decimoputzu», Cagliari.

UGAS, G. 1998a: «Considerazioni sulle sequenze culturali e cronologiche tra l'Eneolitico e l'età Nuragica», Sardinian stratigraphy and Mediterranean Chronology. An
International Colloquium devoted to the Chronology of the ancient Mediterranean, 251-272, Medford.

UGAS, G., 1998b: «Facies campaniformi dell'ipogeo di Padru Jossu (Sanluri-Cagliari)», en F. NICOLIS y E. MOTTES (Eds.), Simbolo ed enigma, il bicchiere campaniforme e l'Italia nella preistoria europea del III millennio a.C., 261-280, Trento.

UGAS, G., 2005: L'alba dei nuraghi, Cagliari.

VANDIER, J., 1952: Manuel d'Archéologie égyptienne, I, Les Epoques de Formation. La Préhistoire, Paris.

VEIGA FERREIRA, O., 1966: La Culture du Vase Campaniforme au Portugal, Serviços Geológicos de Portugal. Memória No. 12 - (Nova Série), Lisboa.

VIGLIARDI A., 1980: «Rapporti tra Sardegna e Toscana nell'Eneolitico finale- Primo Bronzo. La grotta del Fontino nel Grossettano», Atti della XXII Riunione Scientifica dell'Istituto Italiano di Preistoria e Protostoria nella sardegna centro-settentrionale, (Firenze, 1978), 247-288, Firenze.

Recepción: 07-06-2012

Aceptación: 12-06-2013 